\title{
Statistical and Numerical Study of Chipping and Cracking in Segmental Lining
}

\author{
Mohammad Mohtadinia ${ }^{1}$, Mohammad Hossein Ahmadi2*, Milad Manafi Fasaghandis ${ }^{3}$, \\ Behnaz Hallaji Dibavar ${ }^{4}$, Seyed Morteza Davarpanah ${ }^{5}$
}

\footnotetext{
${ }^{1}$ Department of Mining Engineering, Faculty of Engineering, University of Tehran, $16^{\text {th }}$ Azar St, Enghelab Sq, 1417466191 Tehran, Iran

2 Department of Mining and Metallurgical Engineering, Amirkabir University of Technology, 424 Hafez Ave, 1591634311 Tehran, Iran

3 Department of Mining Engineering, Faculty of Engineering, Sahand University of Thechnology, Sahand New Town, 51335/1996 Tabriz, Iran

${ }^{4}$ Department of Mining Engineering: Rock mechanics, Faculty of Engineering, Hacettepe University, 06800 Beytepe, Ankara, Turkey

${ }^{5}$ Department of Engineering Geology and Geotechnics, Budapest University of Technology and Economics, H-1111 Budapest, Műegyetem rkp. 3., Hungary

* Corresponding author, e-mail: m.h.ahmadi@aut.ac.ir
}

Received: 26 March 2020, Accepted: 21 May 2020, Published online: 18 June 2020

\begin{abstract}
Some of the most frequent damages of concrete segments in shield tunnels are chipping and cracking, which are followed by degradation of lining system. In this paper, these types of damages are studied in four subway and two water conveyance tunnels. More than 2100 concrete rings are examined for chipping inspection and another 3000 for determination of the cracking. Statistical analysis of the research data showed that corners of the key and counter-key segments carry the highest number of chipping, while most of the cracking occur in the middle zones and shape of the segments and number of trust jacks affect the cracking pattern. Two kinds of numerical models are used to examine the underlying damages, which are based on geometrical characteristics of tunnel lining and boring machine besides operational mistakes. Findings of the numerical simulation revealed that installation of segmental lining with the least amount of erection tolerances results in low amount of chipping, this is while using key-segments with 12-17 degrees of insertion angle reduces total magnitude of damage due to tensile and compressive stresses. Furthermore, the deviation angle of TBM's jack and segment's axis should never be more than 5 degrees; otherwise even high-quality concrete segments wouldn't remain undamaged. Employment of boring machines with articulated system is proposed in this case.
\end{abstract}

\section{Keywords}

segmental lining, statistical analysis, numerical modeling, key-segments, damage

\section{Introduction}

Concrete segments, the system to support every section of shield tunnels are fabricated in segment factory based on a precise quality control system [1]. However, the pieces go under variety of damages from production stage to utilization in the tunnel. Detriments highly affect the durability of the lining system or at least, cause disorders in their functionality. Generally, the concrete segments might be damaged in any of the following four stages: production in segment factory, transportation to the site, installation process and while utilization in the tunnel [2].

Past studies have shown that about 80 percent of the segmental lining damages are related to construction phase, while the effect of segment quality involves only about 10 percent of the issue [3]. Damages occurring in the pre- installation stages have the capability to be intensified by boring machine and ground forces. So, producing high quality segments and appropriate transportation of them are important factors in having an acceptable lining system.

Damages of concrete segments during production process might be caused by the two general reasons, inappropriate concrete and operational faults [4]. Damages due to unsuitable concrete include bleeding, honeycomb and cracking and increase in permeability, reduction of strength and corrosion of reinforcement are the main consequences of unsuitable concrete $[5,6]$. Concrete segment's cracking at production sites is related to the strain caused by drying shrinkage of concrete. This kind of damage is the result of the reduction in volume of concrete, which is principally 
due to loss of water during the drying process [7]. Proper steam curing cycle has the most important effect on reduction of segment's cracks at production plant [8]. Damages caused by operational mistakes include: improper hanging socket insertion, improper dowel nut insertion, imperfect geometry of steel cage and improper finishing, in a way that every fault has a specific effect on the quality of segmental lining [9].

Concrete segments are transferred to tunnels for installation after achieving adequate strength in manufacturing factory. Corner and edge chipping might happen due to influences of the applied mechanical forces during transportation. This type of destruction is the only kind that addresses the concrete segments during transportation phase, which could be prevented through proper training of the operators to handle the pieces attentively and carefully [2].

Damages in the concrete segments during tunnel construction could be developed in accordance with geological condition of the ground, the route of tunnel, geometrical aspects of the concrete segments, boring machine characteristics and finally, the operational mistakes. During excavation, the stiffer the ground, the higher the reaction force is applied to the TBM and as a consequence advance in a curved path would face problems. On the other hand, when dealing with soft ground, where the reaction force is insufficient, controlling the TBM would encounter difficulties, too. Excavation in the presence of high hydrostatic pressure increases the demand for additional thrust force of TBM jacks. Besides, sudden changes in gradient or direction of tunnel would cause a reduction in the tail clearance that would create some complications in the machine control, which in turn, is being followed by damaging the segments $[10,11]$.

The dimensional tolerances related to the concrete segments should be designed in such a manner that the minimum tolerance in installation of the concrete segments wouldn't damage them [2]. These tolerances are selected according to the demands of the project [12]. Segments with larger dimensions cope with uneasy installation, which might increase vulnerability of the pieces, whilst the segments with smaller dimensions make it easier install the lining, but it requires longer time for excavating the tunnel [1].

Number of the jacks of boring machine must be in accordance with the distribution manner of the stress transferred to the lining of the tunnel and also a proper tail clearance must be selected in order to avoid damage in the concrete segments [12]. Furthermore, in some cases articulated boring machines have to be employed due to the geometry of the curvatures of tunnels [10]. Forces applied by the jacks of TBM along with the forces directed from the ground, when concrete segments are being discharged from the shield, would give a trumpet shape to the ring. Trumpet shape of the lining creates torsion in segments. The torsion not only may cause cracking, but also would be followed by ovalization of the segmental lining. The ovalization would damage the concrete segments by developing some points with high concentration of stress [13].

When the longitudinal joints of the segments are not perfectly sealed up, which is the result of mistakes in installation stage, assemblage of segments especially the key one would be difficult and risky [13]. The matter gets crucial under the circumstances, where the key segment is installed to one of the jacks of boring machine. This heightens the probability of torsion and damage in the key segment and its adjacent segments [13]. Uneven lateral joints, which take place due to tolerance in the thickness of packing materials along with the tolerance occurring in installation and production of concrete segments are themselves some other factors in damaging them [14].

Step deformation of the rings, chipping, damage in gasket groove and in general, any parameter preventing a complete and perfect contact and attachment in between the two adjacent segment's gasket would cause defect in sealing performance of the lining system. Eventually, total result of the above mentioned factors shall be followed by the deviation of the TBM's jacks in relation to the concrete segment's axis. This can be considered among the most important reasons of damaging concrete segments [13]. It should be noted that, tolerances of 1-2 millimeters, in installation of concrete segments, could generate displacements up to 10 times larger than the above mentioned mistake [14]. In comparison with longitudinal joints, lateral joints are mostly effected by the factors that are destructive to concrete segments $[15,16]$.

Freeze-thaw cycles, abrasion, erosion, cavitation, and high temperature are the most significant physical reasons of damaging concrete segments during exploitation of tunnel. Carbonation, sulfate, and acidic attack could be considered among chemical factors of the concrete segments destruction while utilizing the tunnel [5]. Forces applied by earthquake, tunnel excavation or founding new structures along with an already existing tunnel and asymmetrical settlement, result in disturbance of lining [17]. An outstanding example of the case is the shield tunnel of the Taipei rapid transit system [18]. 
In this article, chipping and cracking of concrete segments are statistically and numerically examined. Present study was developed based on the statistical data obtained from field studies on segmental lining of Iran shield tunnel projects, namely Tabriz line 1, Mashhad line 2, Tehran lines 3 and 7 subways and two water conveyance tunnels of Golab and Chamshir.

\section{Statistical examination of segmental lining damages}

Different kinds of concrete segments are used in tunnels, upon which statistical studies have been conducted. Fig. 1 shows general geometrical specifications of the examined segments and tunnels. According to this figure, the segmental lining of tunnels can be classified in the three groups as rectangular in the lines 3 and 7 of Tehran subway tunnels,

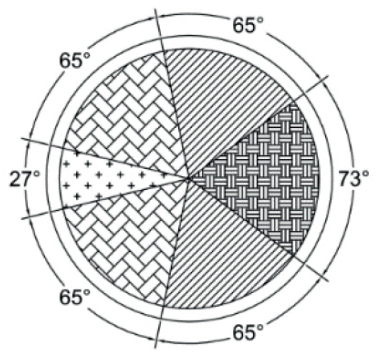

Tabriz Line 1 Subway Tunnel Inner Radius : $3.00 \mathrm{~m}$ Outer Radius : $3.30 \mathrm{~m}$

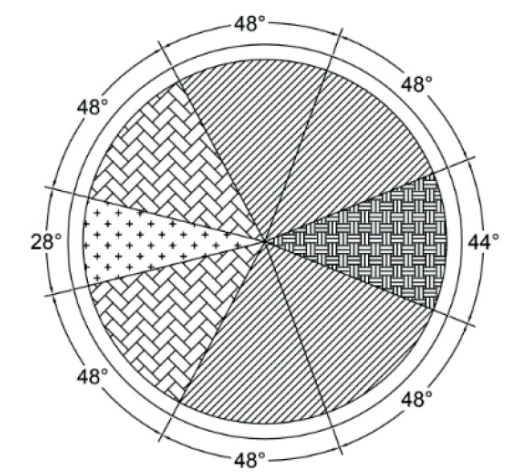

Mashhad Line 2 Subway Tunnel Inner Radius : $4.20 \mathrm{~m}$ Outer Radius : $4.55 \mathrm{~m}$

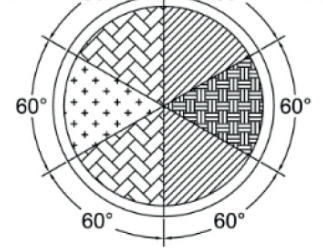

Chamshir Water Conveyance Tunnel Inner Radius : $2.30 \mathrm{~m}$ Outer Radius : $2.55 \mathrm{~m}$
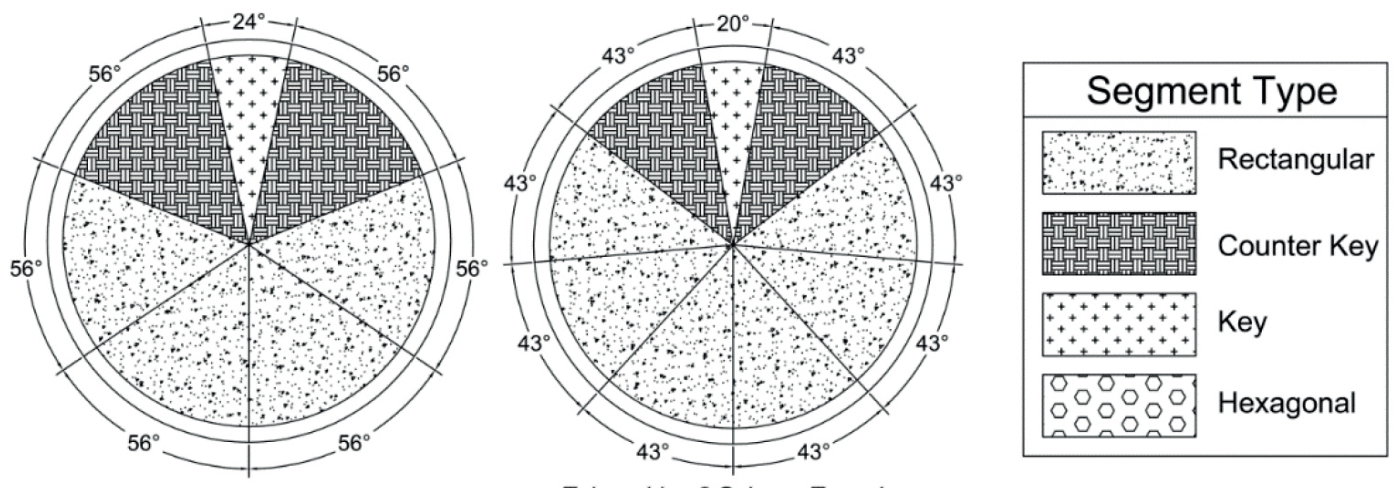

Tehran Line 7 Subway Tunnel Inner Radius : $4.125 \mathrm{~m}$ Tehran Line 3 Subway Tunnel Inner Radius : $4.075 \mathrm{~m}$ Outer Radius : $4.475 \mathrm{~m}$ Outer Radius : $4.425 \mathrm{~m}$

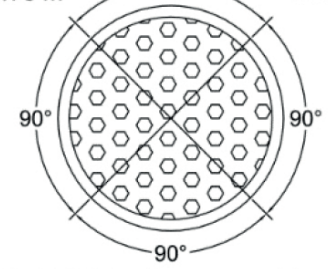

Golab Water Conveyance Tunnel

Inner Radius : 2.250 m

Outer Radius : $2.500 \mathrm{~m}$

Fig. 1 General geometrical specifications of the segmental linings in the studied tunnels 
hexagonal in Golab water conveyance tunnel, parallelogram in Tabriz subway line 1, Mashhad subway line 2 tunnel and Chamshir water conveyance tunnel. To study the chipping and cracking damages, the segmental lining of the above mentioned tunnels are summarized in parts 1, 3 and 4 according to their shape or position in a ring (being near to the key segment) and also each part is divided into 3 or 9 zones for detailed investigation. Fig. 2 shows the zoning of mentioned concrete segments in surveyed tunnels.

\subsection{Chipping of segmental lining in tunnels}

Segmental Lining of Tehran subway line 3 includes nine segments 6 segments of which are rectangular, 2 are counterkey segments and the last one is key segment. Number of the studied rings in this tunnel is 109 and according to Fig. 2, when data gathering for chipping investigation these segments have been classified in 9 zones. Fig. 3 shows the chipping magnitude of Tehran subway line 3 segments. This parameter is calculated by dividing total number of chippings in each zone to the total number of damaged segments.

As it can be inferred from Fig. 3, zones 7, 8 and 9 of the rectangular segments, zones 16,17 and 18 of counter-key segments, and zones 25 and 27 of the key segments have the maximum number of chippings in this tunnel. It is noteworthy that zones 25 and 27 in the key segment have the maximum amount of chipping.

Segmental Lining of Tehran subway line 7 includes seven segments, four segments of which are rectangular, 2 segments are counter-key and one is a key segment. Number of the studied rings in this tunnel is 1000 . Considering the number of rings when data gathering for chipping, segments weren't zoned and the amount of chipping was represented according to the segment type. Fig. 4 shows the chipping magnitude in each segment type, maximum amount of which is related to counter-key segment. The same study was done on line 3 segments and it was concluded that, the counter-key segment has the maximum overall amount of damage, Fig. 4.

Number of the rings which have been studied in Tabriz subway line 1 was 345 rings. Each ring of the tunnel includes six concrete segments, four segments of which are parallelogram, one segment is a counter-key and one is key segment. 720 rings were studied in line 2 of Mashhad subway. Each ring of the tunnel is composed of six parallelogram segments, one counter-key segment and one key segment. Zoning of the segments of these two

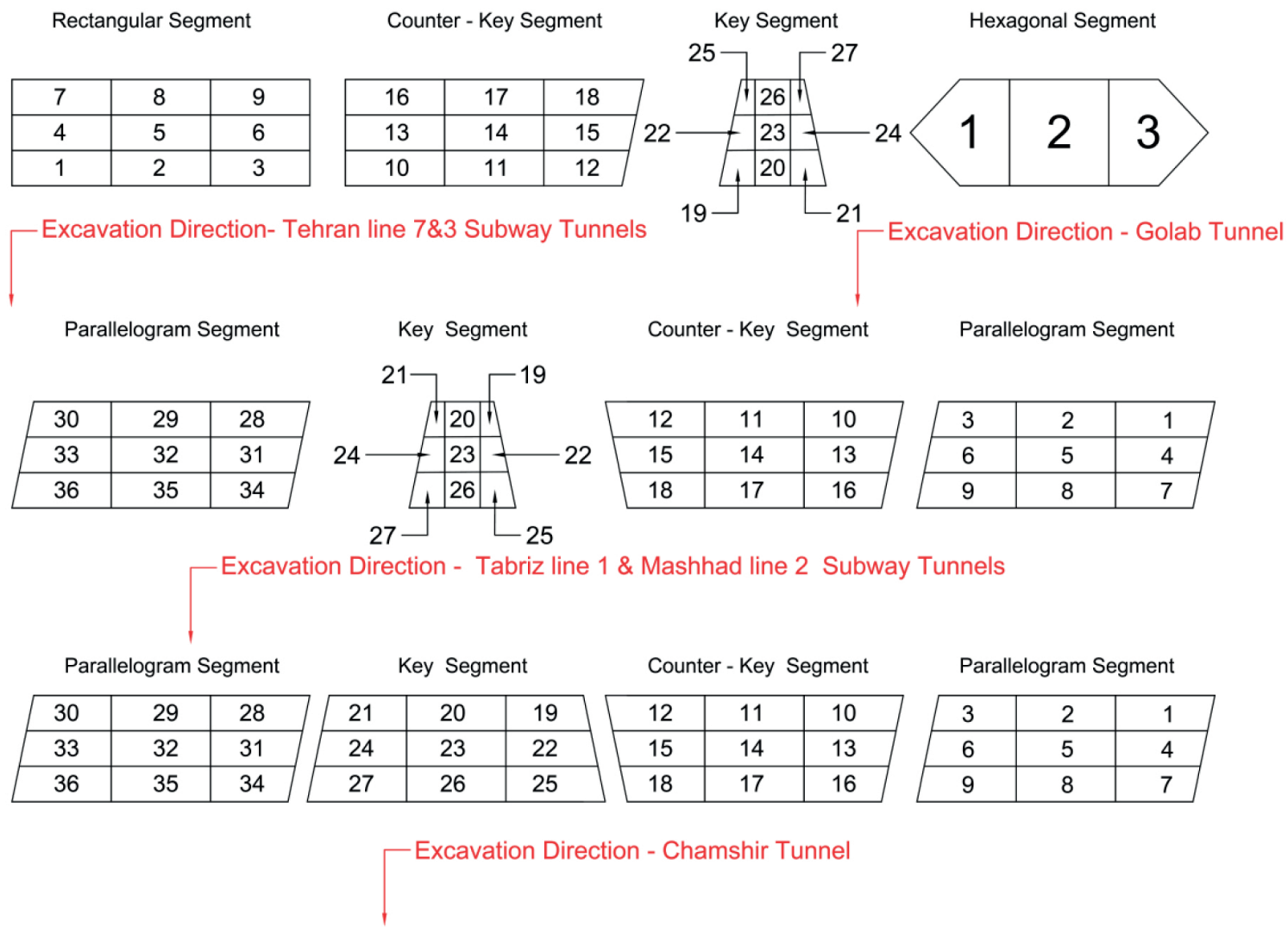

Fig. 2 Zoning of the studied segmental linings for statistical examination 
tunnels is shown in Fig. 2. Zones 1-9 refer to parallelogram segments, zones 10-18 are for counter-key segment, zones 19-27 and 28-36 refer to key segment and keyadjacent segment, respectively. According to Fig. 5, which shows the statistical analysis results, it could be concluded that the maximum amount of chipping occurs in zone numbers 3, 12, 16, 18, 21, 25, 28 and 36. Zone 28 is related to key-adjacent segment which has the maximum amount of chipping. It is also presented in Fig. 6 where key-adjacent segment has the maximum amount of chipping.

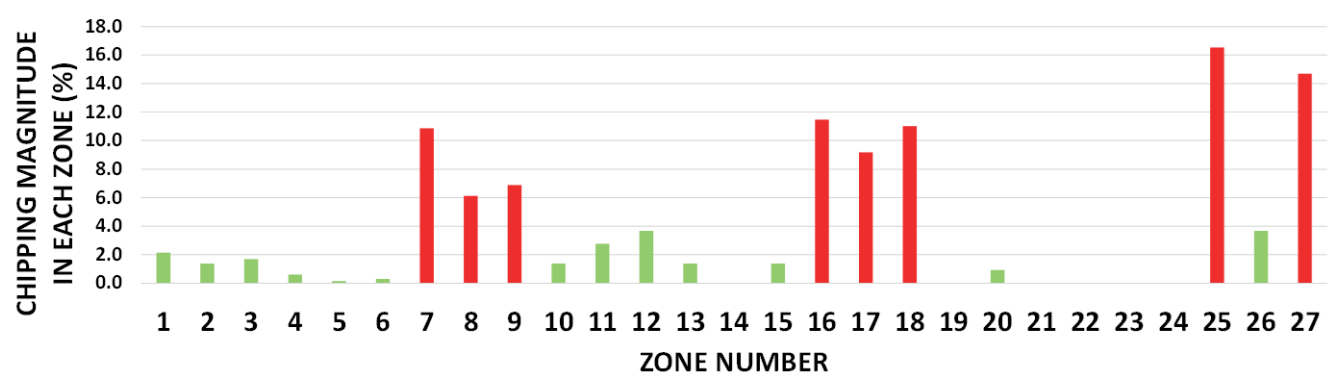

Fig. 3 Chipping magnitude in Tehran line 3 subway tunnel lining

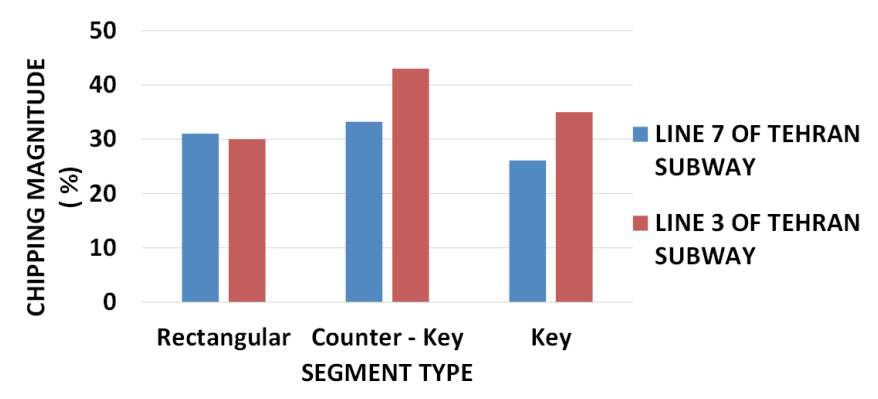

Fig. 4 Chipping magnitude in Tehran subway lines 3 and 7 tunnels linings

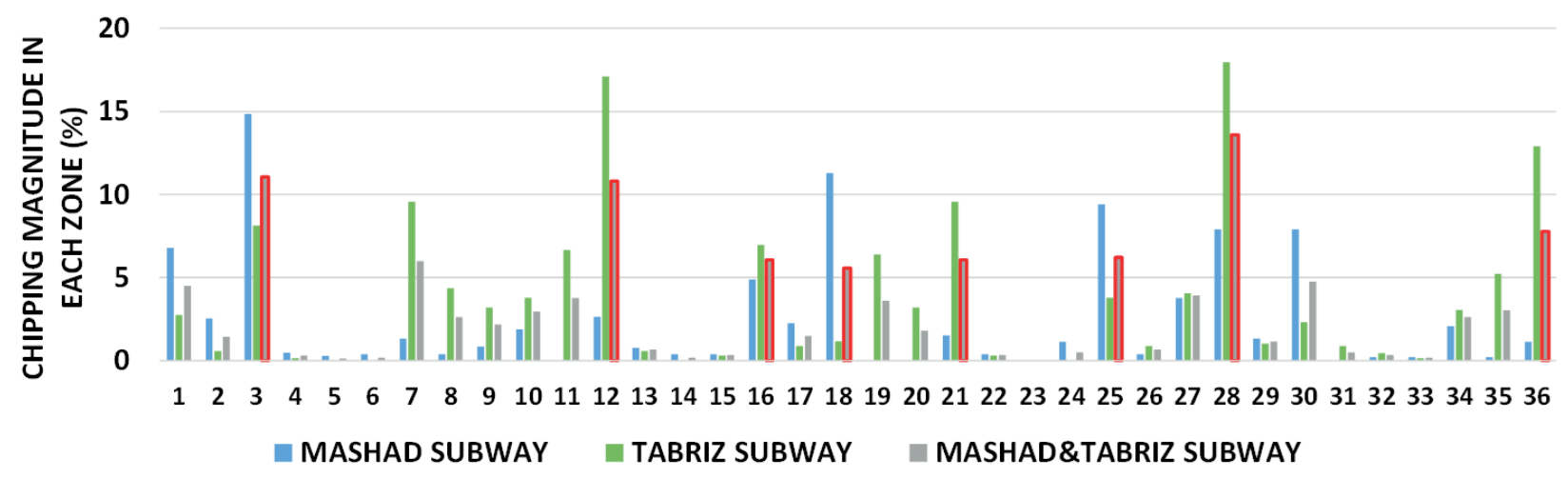

Fig. 5 Chipping magnitude in Tabriz subway line 1 and Mashhad subway line 2 tunnels

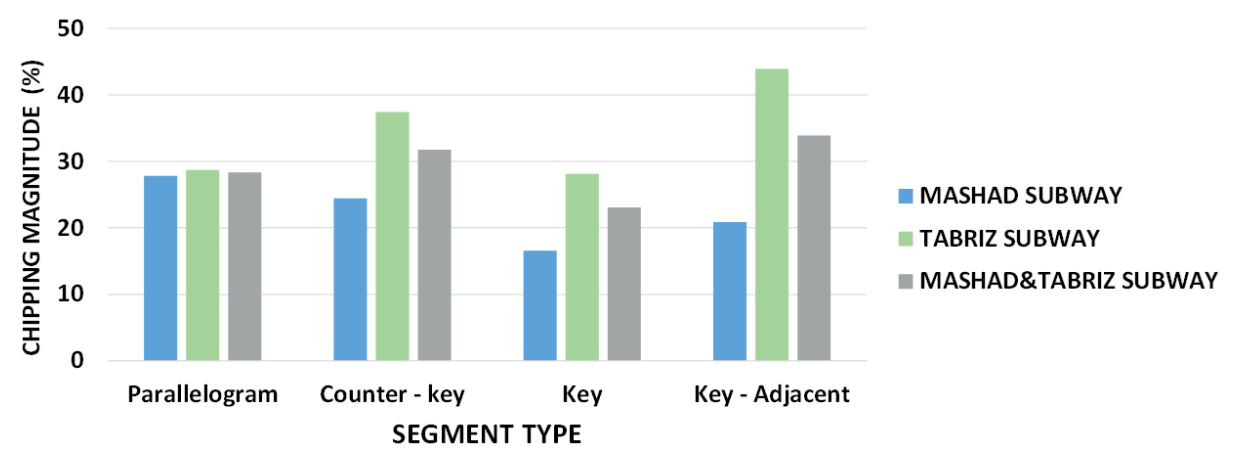

Fig. 6 chipping magnitude in different segments 
Figs. 7(a) and 7(b) show the chipping of the concrete segments in line 7 of Tehran subway and line 1 of Tabriz subway, respectively. Statistical inspection of chippings in concrete segments shows that counter-key segments in rectangular linings and key-adjacent segments in parallelogram linings have the maximum amount of chipping. Furthermore, corners of the key segment in parallelogram and rectangular linings are highly vulnerable to damage. Contact surfaces of the two adjacent segments in the same ring could be the reason for chipping in longitudinal joints and chipping of lateral joints could be resulted from TBM's jack's forces as well as contact of the segments of the adjacent rings. Also, non-uniform spacing of both sides of the segments creates uneven lateral joints, which could be developed into damages in concrete segments.

\subsection{Cracking of segmental lining in tunnels}

For investigation of the cracking in the concrete segments, 1000 rings of Tehran subway line 7, 1000 rings of Golab and 961 rings of Chamshir water conveyance tunnels were selected and examined. Fig. 8 shows the amount of cracking in concrete segments of the underlying tunnels. Zone numbers of these figures are in accordance with Fig. 2. Red columns of the following figures represent the highest amount of cracking in segments. As it can be inferred from these figures, middle zones of the segments have the highest amount of cracking. Fig. 9 shows another aspect of

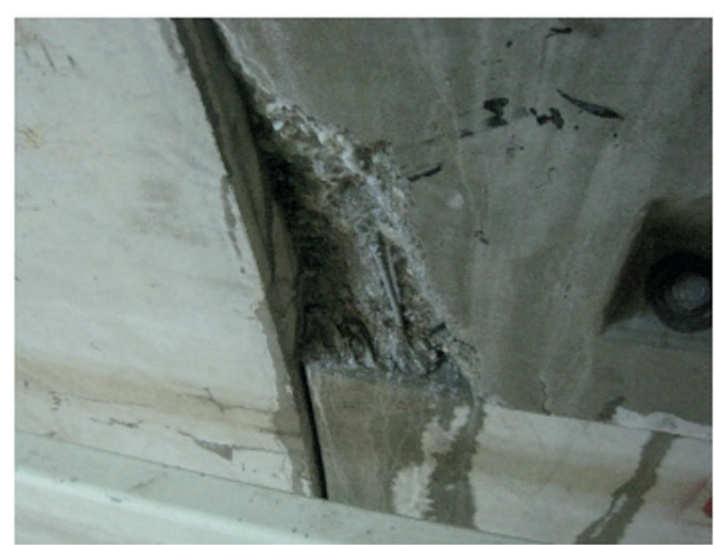

a

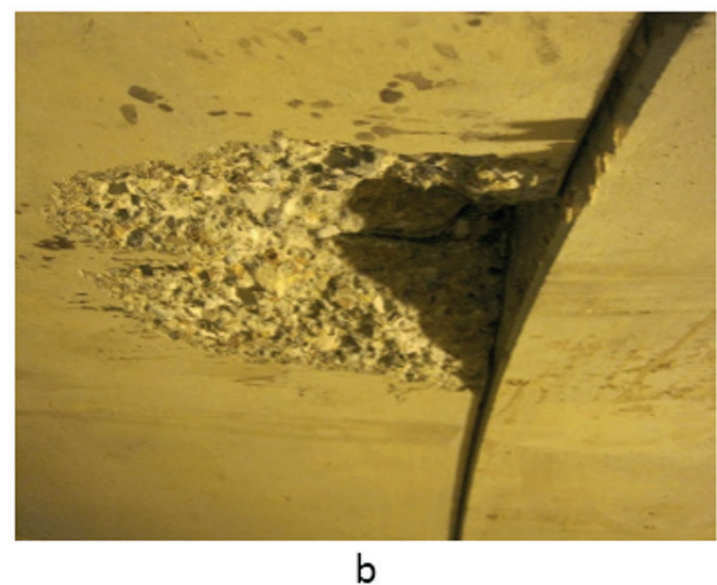

Fig. 7 Concrete segments chipping, a) line 7 of Tehran subway tunnel, b) line 1 of Tabriz subway tunnel

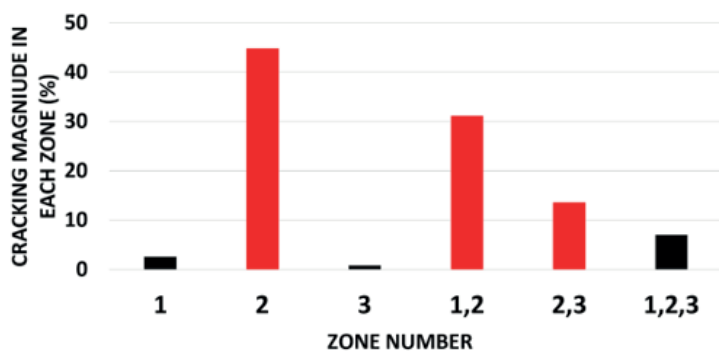

b

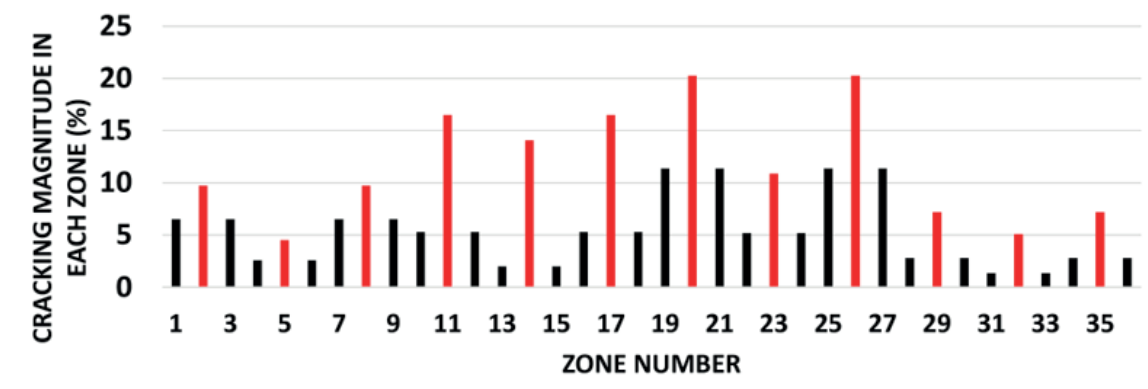

C

Fig. 8 Cracking magnitude in a) Tehran subway Line 7 tunnel, b) Golab water conveyance tunnel, c) Chamshir water conveyance tunnel 

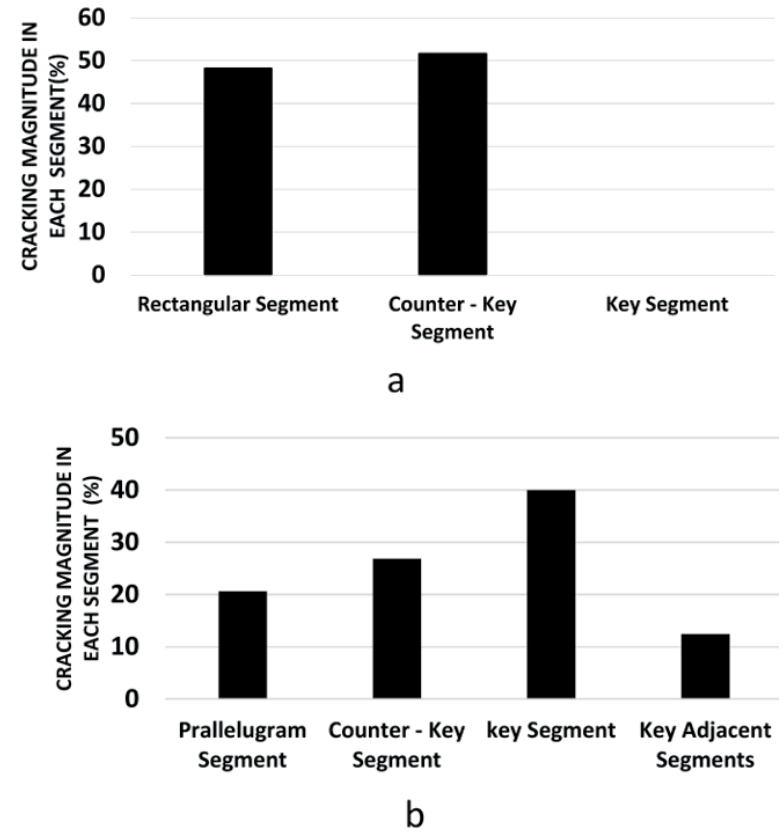

Fig. 9 Cracking magnitude in each segment type of a) Tehran line 7 subway tunnel, b) Chamshir water conveyance tunnel

cracking. In line 7 of Tehran subway, all of the segments, except for the key one have the same amount of cracking, Fig. 9(a), but in Chamshir water conveyance tunnel, it is the key segment, which is mostly cracked (Fig. 9(b)). The TBM of Tehran subway line 7 has nineteen thrust jacks, eighteen of which are for hexagon and counter-key segments and the last one is for key segment.

So there is low possibility on the creation of tension zone in the middle of the key segment and hence, this segment has the lowest amount of cracking. On the other hand, the TBM of Chamshir tunnel is composed of twelve jacks and each segment is in contact with 2 jacks, so in this case creation of tension zone in the middle part of each segment is expected. In this case, it is the shape of the parts that determines the damage rate. So, the counterkey and key-segments are highly vulnerable to damage. Fig. 10 shows examples of cracking in concrete segments of the underlying tunnels. It can be concluded from statistical examination of the cracking that such type of damage appears, generally, not in the edges, but within the inner zones. Furthermore, the shape of the segment and number of thrust jacks per piece are other parameters which should be taken into account while cracking examination.

\section{Numerical modelling}

Operational mistakes, defects in design of lining system, and inappropriate selection of boring machine are the possible sources of concrete segment's damages. Numerical

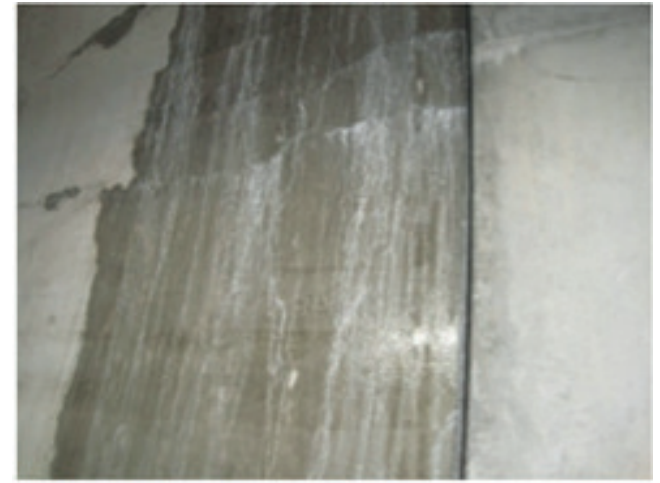

a
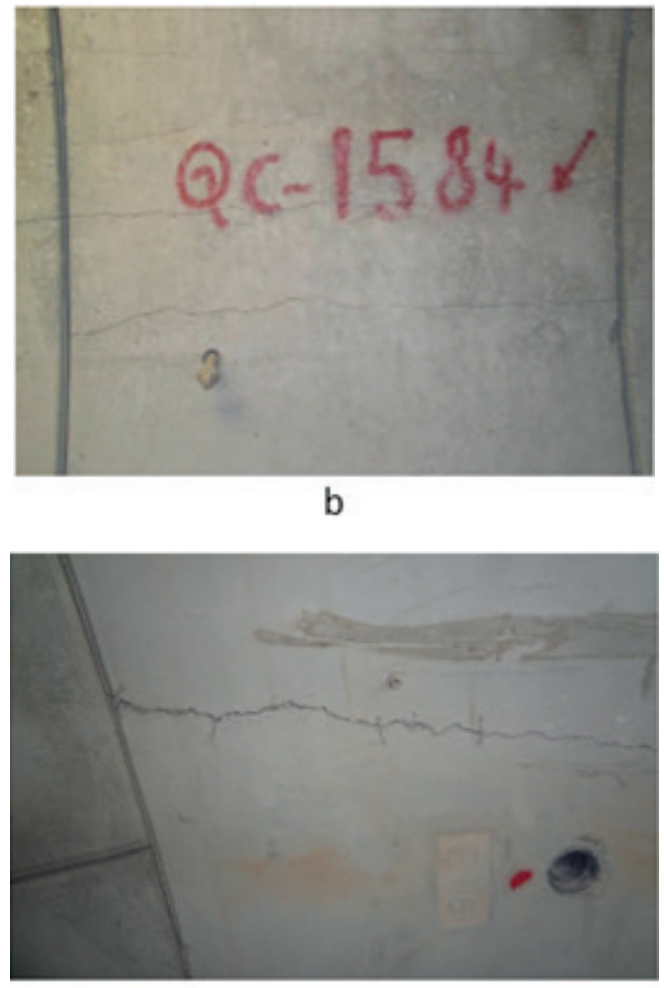

C

Fig. 10 Cracking in the concrete segments a) Tehran subway line 7 tunnel, b) Golab water conveyance tunnel, c) Chamshir water conveyance tunnel

modeling is used to examine effect of the underlying factors on occurrence of chipping and cracking, which are described in the following sections.

\subsection{Numerical model geometry and boundary conditions}

According to the outcomes of the statistical analysis of chipping in concrete segments, most of the damages occurs on key segment and the ones adjacent to it. Among the other parameters, geometrical characteristics of key segment especially the insertion angle, which is described in Fig. 11(a) has significant effect on the structural behavior 
of it. According to the Japanese standard of shield tunnels, the insertion angle of key segment can be between 7 and 22 degrees [19]. To study the effect of geometrical aspect on the magnitude of damage, four numerical models of key segments with insertion angles of 7, 12, 17 and 22 degrees are prepared. Fig. 11(b) and Fig. 11(c) show the geometry and boundary conditions of these models. The numerical model of key segment includes two kinds of loadings, axial and radial types. The radial loading is used to model the forces applied by the ground and grout, and, the axial loading is used to activate the frictional force relevant to the surfaces in between the key segment and the adjacent ones (Fig. 11(d) and $€$ ). In fact, the solution for the numerical model consists of two steps. At first, parts 3 (Fig. 11(b)) are moved forward until the contact force between the key segment and adjacent ones in the middle part gets activated. If frictional force lacks, the key segment has no obstacle in $\mathrm{y}$-direction and therefore it will move in this direction under the radial force, so the numerical model becomes statistically unstable. As the frictional force between the key and adjacent segments reaches adequate magnitude, the effect of axial force will be gradually eliminated from the model solution process. According to the studies taken place, the applied loads to the tunnel lining system have some values of $12.5 \mathrm{KPa}$ up to $650 \mathrm{KPa}$ [19]. Some 200 to $300 \mathrm{KPa}$ could also be assigned to radial grout force [17]. The maximum force being applied to the model equals $1.04 \mathrm{MPa}$. The magnitude of load has been chosen to determine the maximum bearing capacity of key and adjacent segments. Keeping in mind the asymmetric behavior of the applied

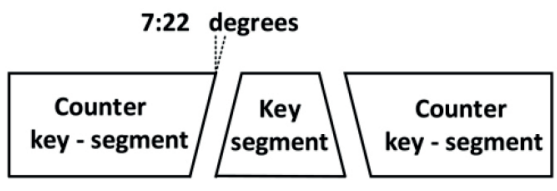

a

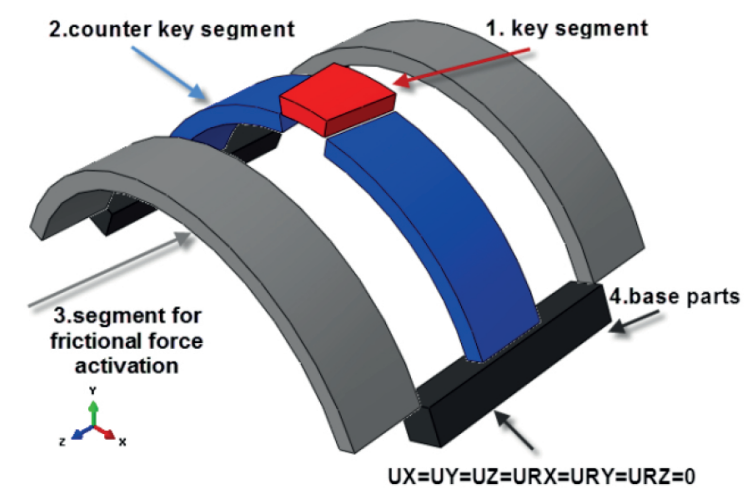

b
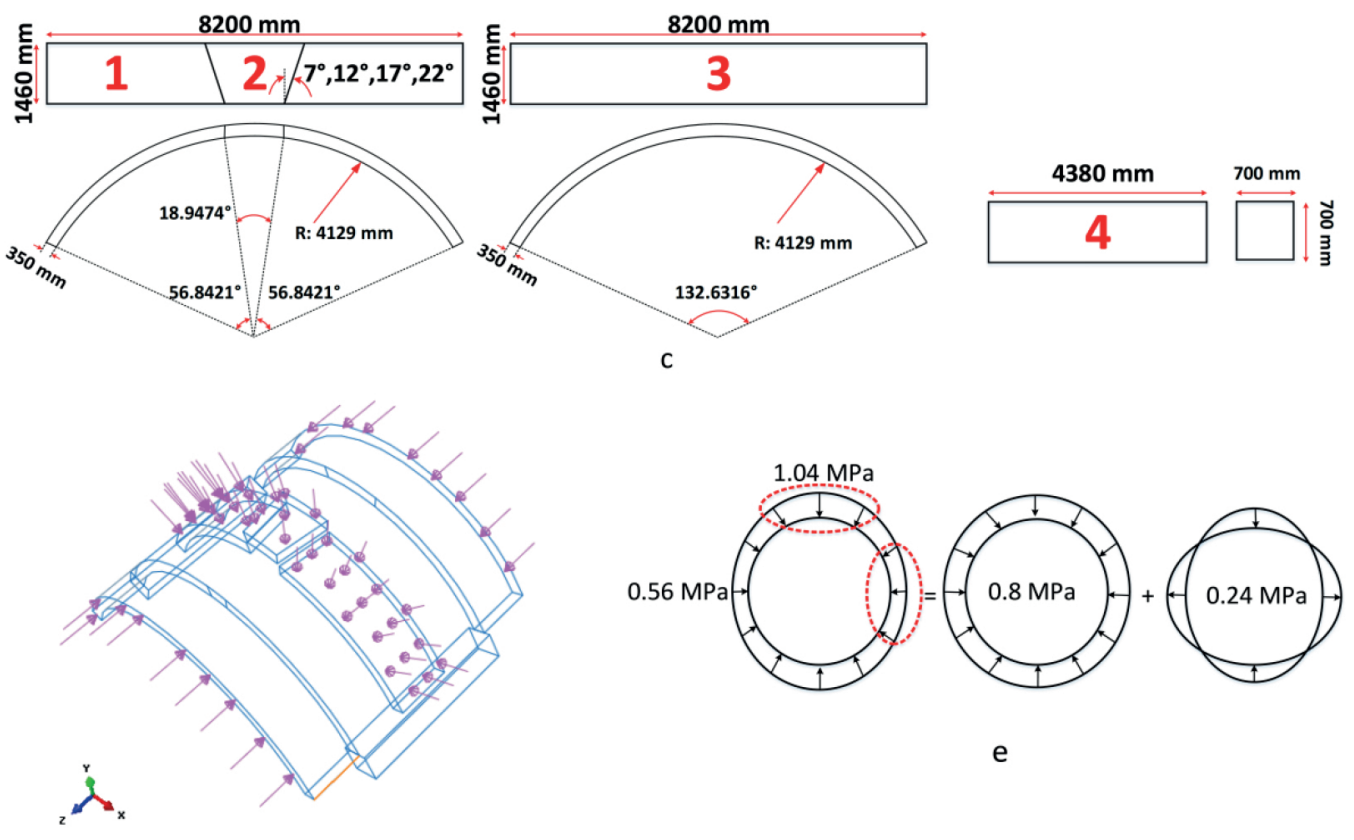

e

d

Fig. 11 Key segment model a) Insertion angle definition, b) Parts of the model and their functions, c) Dimension of model parts, d and e) Loads applied to numerical model 


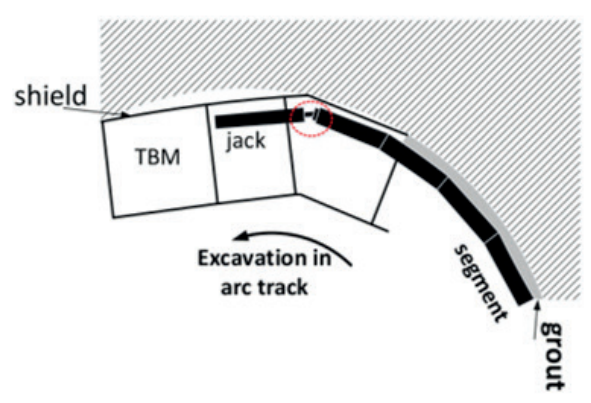

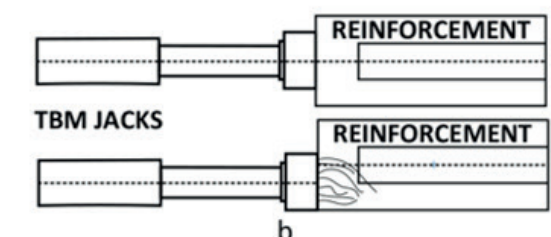

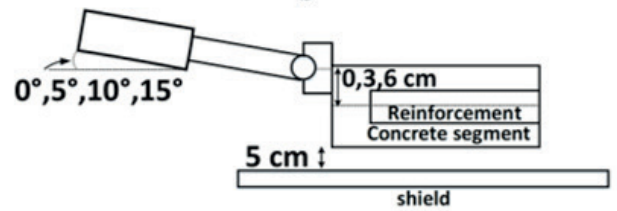

c

Fig. 12 Thrust jack model a) tunnel excavation in a curved route. b) Jack deviation caused by operator's mistake, c) Modeling of the applied forces by TBM's jack to concrete segments

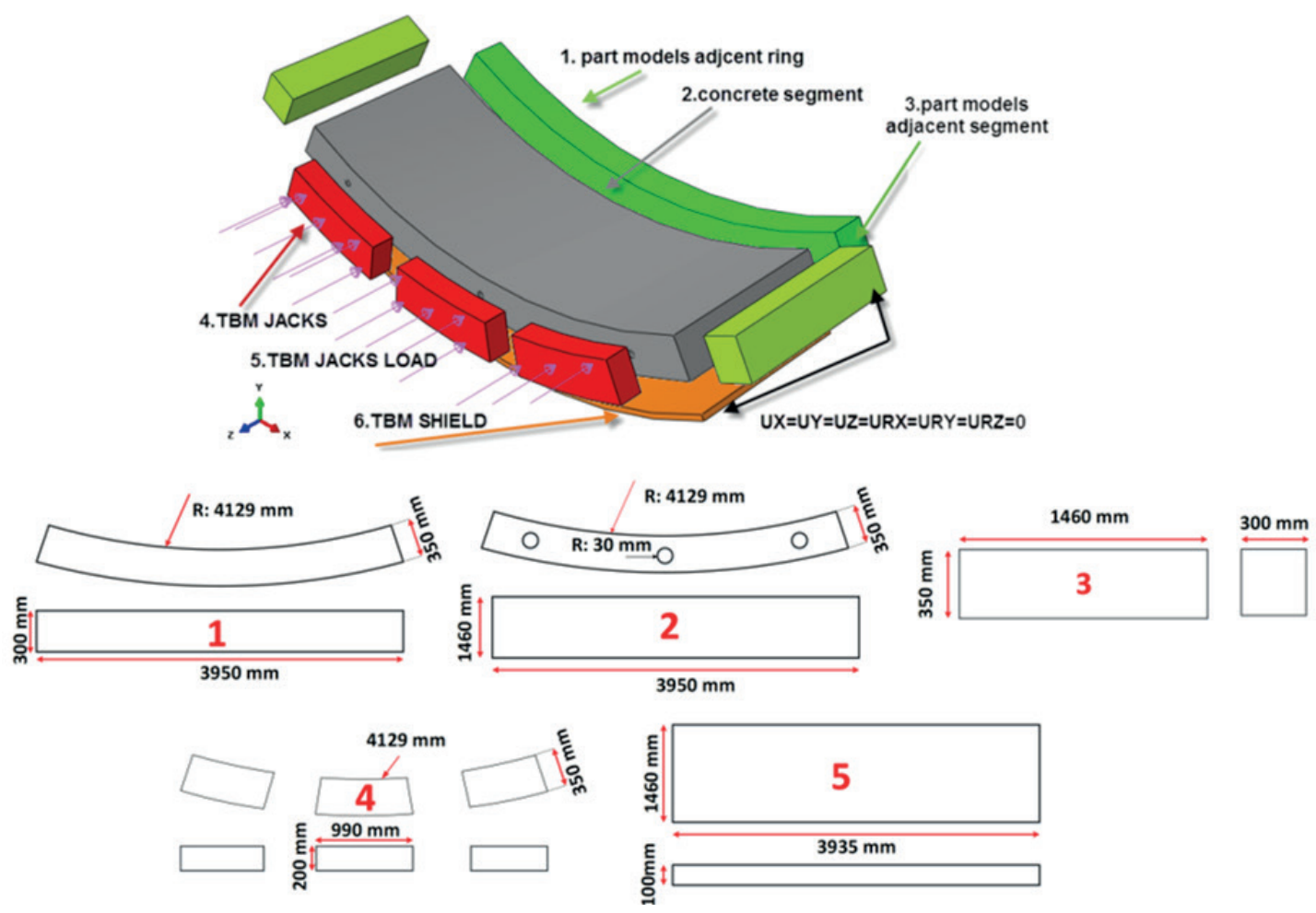

Fig. 13 Geometry of parts related to thrust jack model

load to the lining according to the mentioned loading manner, two sets of models is examined, key segment on the ceiling and another one, key segment on the wall. Other important boundary conditions of key segment model are presented in Fig. 11(b). This study is done while assuming that no tolerances in installation stage is occurred.

Another numerical model was developed for examination of cracking damage. When the force applied by the jacks of the TBM is not in alignment with the axis of the segments, the outcome could be a bending moment and would be followed by tensile stresses. The resulted stresses would develop cracking in segments. Most of the time, this event arises in a curve alignment of the tunnel routes or operational mistakes in segment's installation process (Fig. 12(a)). In most cases, the above-mentioned reasons result in deviation of jacks from the middle of the thickness of the segment (Fig. 12(b)). According to Fig. 12(c), numerical examination of cracking includes 12 models. In these models, it is assumed that the axis of TBM jacks have $0,5,10$ and 15 degrees of deviation from the axis of segments besides 0,3 and $6 \mathrm{~cm}$ deviation from the center line. It should be noted that the segments appointed outside the curve routes are simulated. Fig. 13 shows the geometry of the numerical model. Adjacent ring and segments, TBM jacks and shield are modeled by parts $1-4$, respectively. The magnitude of the thrust force is $3 \mathrm{MPa}$. 
In key segment and thrust jack models, all the contact surfaces between the concrete segments are modeled by using penalty contact type with the frictional coefficient of 0.3 . Finally, steel bars of the concrete segments are modeled by embedding elements into the adjacent concrete elements.

\subsection{Constitutive model and parameters}

Concrete damage plasticity (CDP) is used for numerical simulation of concrete segments. This constitutive model is based on principles of plasticity. Yielding of concrete structures is determined by considering damages due to compressive and tensile stresses. The damage rate is calculated by reduction in modulus of elasticity, which is described by using two scalar parameters of dt (tensile stress damage coefficient) and dc (compressive stress damage coefficient). These two parameters depend on plastic strain, temperature and other elements, which are determined according to the conditions of the case. Values $0-1$ are those, which could be assigned to the underlying two parameters [20]. For instance, $d_{t}$ or $d_{c}=1$ indicates that the elements of model are totally damaged under tensile or compressive load while dt or $d_{c}=0$ is a sign of intact elements.

Stress-strain behavior of concrete under compressive and tensile stresses, dt and dc, elasticity modulus, Poisson ratio and density are the main parameters of concrete damage plasticity. This constitutive model also needs some supplementary data as:

$\sigma_{b 0} / \sigma_{c 0}$ : Biaxial yield stress to uniaxial yield stress ratio of concrete sample. Default value of these parameters is considered to be 1.16 .

$\psi\left(\theta-f_{i}\right)$ : Dilation angle which is measured under hydrostatic stress.

$\varepsilon\left(\theta-f_{i}\right)$ : States changing mode of dilation angle based on the hydrostatic stress. It is considered as a default value of 1 and indicates that the amount of dilation angle remains unchanged in a wide range of hydrostatic stress values.
$K_{C}$ : Expressing invariable ratio of tensile to compressive stresses. This parameter has a value in the range of $0.5-1$. Default value is considered to be 0.666 [21].

Table 1 presents the stress-strain behavior of the concrete modeled in this paper. These data are related to Tehran subway line 7 concrete segments. The elasticity modulus (GPa), Poisson ratio (-) and density $\left(\mathrm{Kg} / \mathrm{m}^{3}\right)$ are $34.3,0.19$ and 2406, respectively [9].

The magnitude of supplementary parameters, $\sigma_{b 0} / \sigma_{c 0}$, $\psi\left(\theta-f_{i}\right), \varepsilon\left(\theta-f_{i}\right)$, and $K_{C}$ are assumed to be $1.12,38,1$ and 0.666 , respectively.

Plastic constitutive model is used for simulation of steel bars, perfect. Parameters of this model are displayed in Table 2 .

\subsection{Results and analyses}

Two subjects are studied in key segment model, which are examination of the amounts and location of the damages in concrete segments being under radial loading of the ground and grout in the two different positions of the key segment, on the top center and the side wall, and also, investigation of the moment-rotational behavior of the longitudinal joints between the key and key-adjacent ones.

Figs. 14 and 15 present the damage of key and key-adjacent segments due to tensile stress when the key part is placed on the ceiling of tunnel. As it can be seen in the figures, the amount of damage is reduced from 7 degree key segment to 22 degree. It is worth mentioning that the damages of key segments are in the inner curve of the concrete segments so it can be seen from the inside of tunnel while the damages of key-adjacent parts, which mostly occur at the nearby of the contact surface with other segments are on the outer curve of lining.

Damages resulted from compressive stress aren't significant and they only occur in the corners of key and keyadjacent segments as shown in Fig. 16. This figure is rela-

Table 1 Constitutive model parameters of concrete [9]

\begin{tabular}{lcccc}
\hline & Compressive Stress & Compressive Damage & \multicolumn{2}{c}{ Tensile Stress } \\
Yield Stress (MPa) & Inelastic Strain (-) & $d_{c}$ & Yield Stress (MPa) & Inelastic Strain (-) \\
\hline 17.6 & 0 & 0 & 1.7 & 0 \\
23.6 & 0.00005 & 0 & 2.4 & 0.0001 \\
35.1 & 0.00006 & 0 & 1.6 & 0.0005 \\
47.2 & 0.00011 & 0 & 0.7 & 0.0008 \\
58.5 & 0.00051 & 0 & 0.2 & 0.0017 \\
47.1 & 0.00171 & 0.2 & 0.05 & 0.9 \\
23.7 & 0.00381 & 0.6 & 0.9 & 0.0027 \\
6.2 & 0.00788 & 0.9 & & 0.95 \\
\hline
\end{tabular}


Table 2 Constitutive model parameters of steel reinforcement [9]

\begin{tabular}{lccc} 
Density $\left(\mathrm{Kg} / \mathrm{m}^{3}\right)$ & Poisson Ratio & $\begin{array}{c}\text { Elasticity } \\
\text { Modulus }(\mathrm{GPa})\end{array}$ & $\begin{array}{c}\text { Yield Stress } \\
(\mathrm{MPa})\end{array}$ \\
\hline 7200 & 0.2 & 200 & 345 \\
\hline
\end{tabular}

ted to the 7 degree key segment, which has the maximum amount of compressive damage in comparison with other key parts. Finally, this conclusion is also true for the case when the key segments is placed on the side wall of tunnel.

When the key segment is placed on the side wall of tunnel, both key and key-adjacent segments incur considerable amount of damage. Fig. 17 and Fig. 18 show the damaged key and key-adjacent segments, respectively. According to Fig. 17, the amount of damage is decreased when the insertion angle increases from 7 degrees to 22 degrees. In this case, the damage happens on the outer surface of segment and it isn't visible from the inside of the tunnel and also Fig. 18 indicates that maximum damage in the key-adjacent segments occurs at the contact surface between the key-adjacent segments and other segments as well as contact surface with the key one.

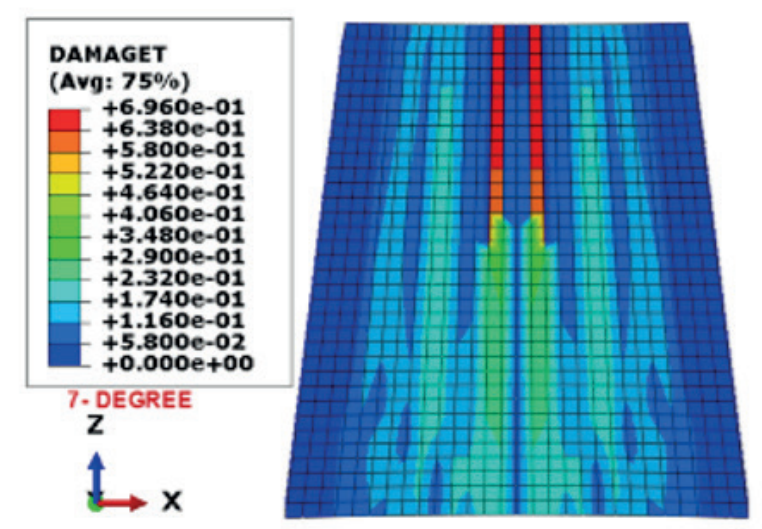

a

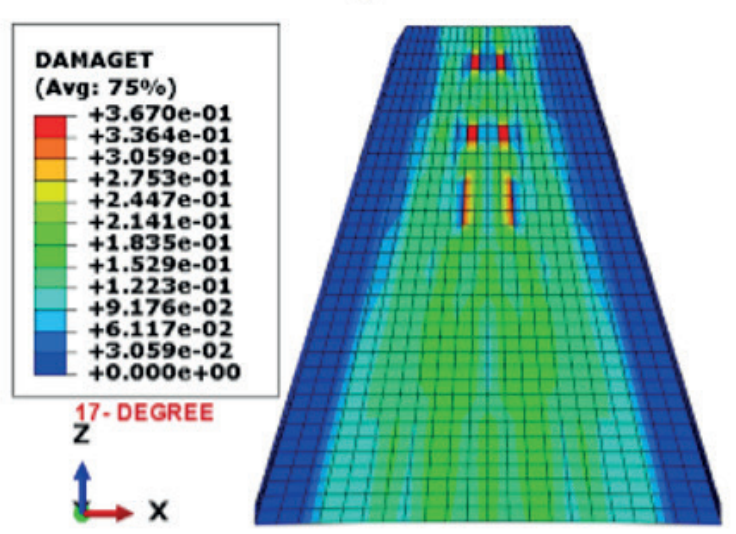

C
As it was mentioned in the previous paragraph, numerical model doesn't show any significant sign of damage due to compressive stress. The reason for this phenomenon could be related to the main assumption of the numerical model, which is perfect installation of segments without any tolerances. Taking this into account, if a maximum possible load were applied to the lining, no chipping would happen on the segments. Therefore, in case of segments erection with a minimum tolerance, the quantity of damages caused by the compressive stress, or chippings, becomes minimal. On the other hand, if producing a concrete with a high tensile strength is feasible, the damage caused by tensile stress shall be removed. In these cases, employing fiber to reinforce the segment could certainly help reduction of this sort of damages. For further study, displacements of the key segments are observed in three directions of $\mathrm{X}, \mathrm{Y}$ and $\mathrm{Z}$. The longitudinal direction $\mathrm{X}$ is along the tunnel radius. The latitude $Y$ direction is along height of the tunnel, and the $\mathrm{Z}$ direction is along the tunnel route. The most essential factor of the three directions is displacement of the parts along $\mathrm{Z}$ axis, which is along the

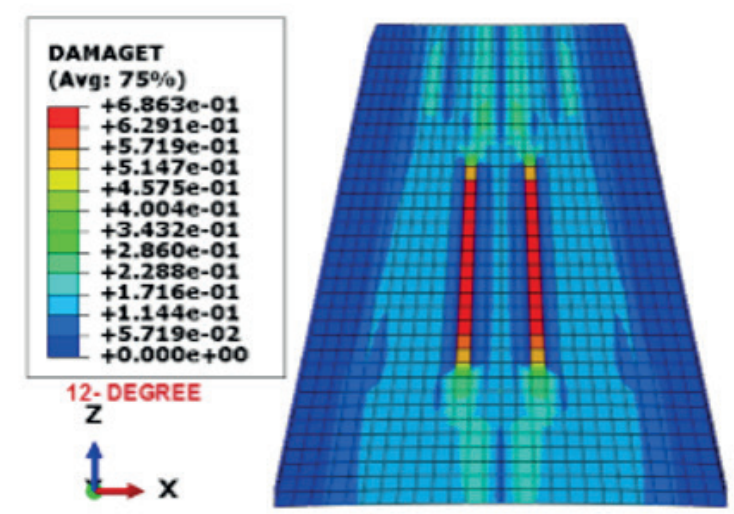

b

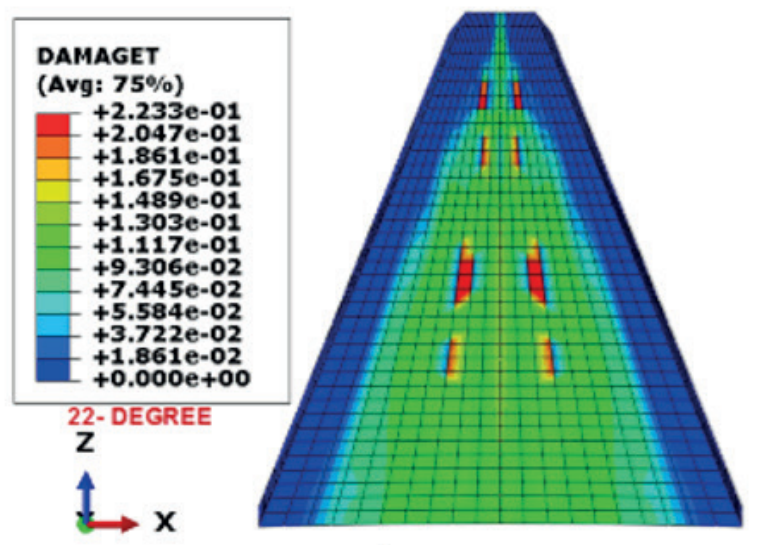

d

Fig. 14 Damages of key - segment due to tensile stress (key segment on the ceiling) Key segment insertion angles a) 7 degree, b) 12 degree, c) 17 degree, d) 22 degree 

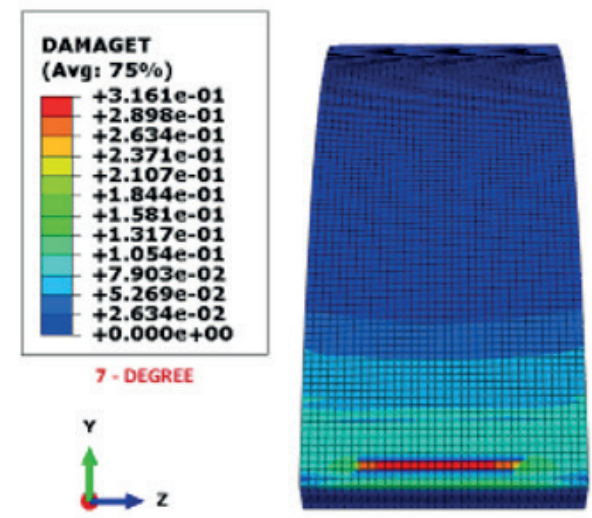

a

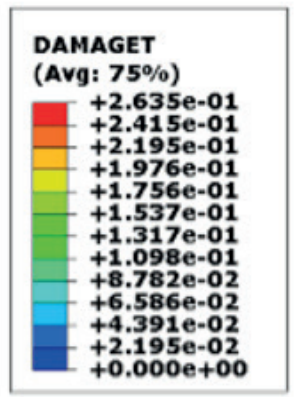

17 - DEGREE

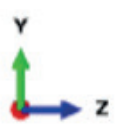

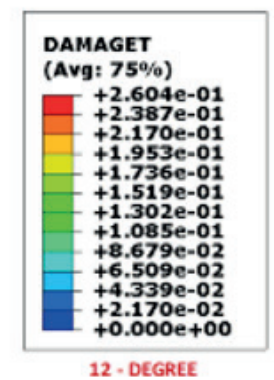
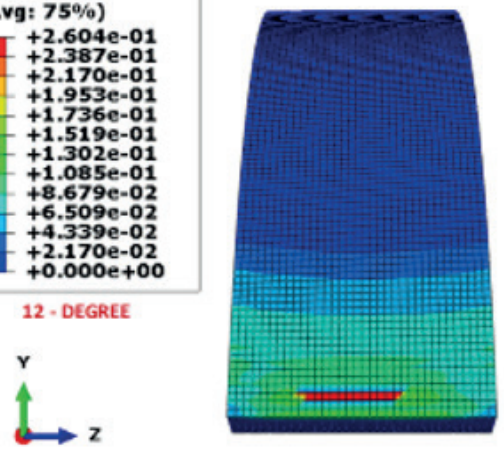

b

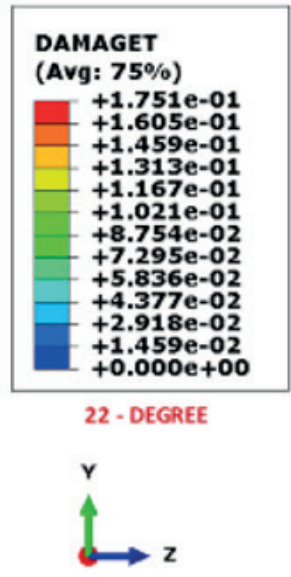

Fig. 15 Damages of key - adjacent segment due to tensile stress (key segment on the ceiling); Key segment insertion angles a) 7 degree, b) 12 degree, c) 17 degree, d) 22 degree

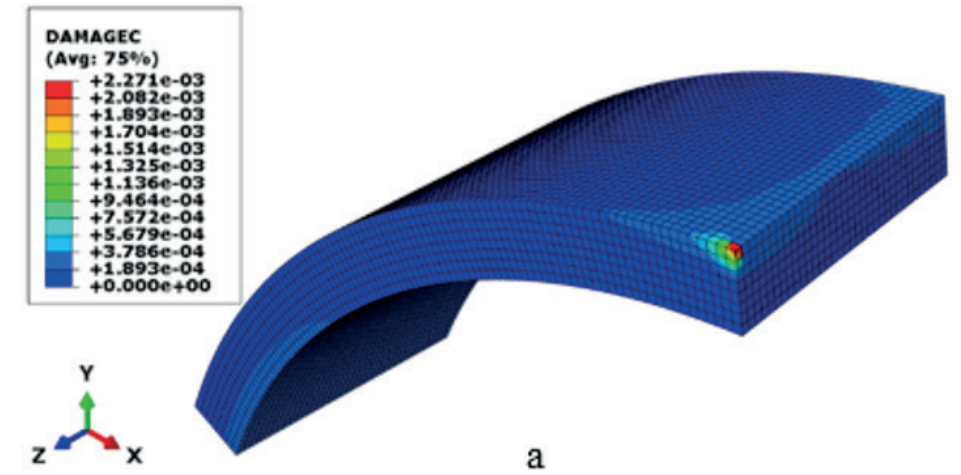

a

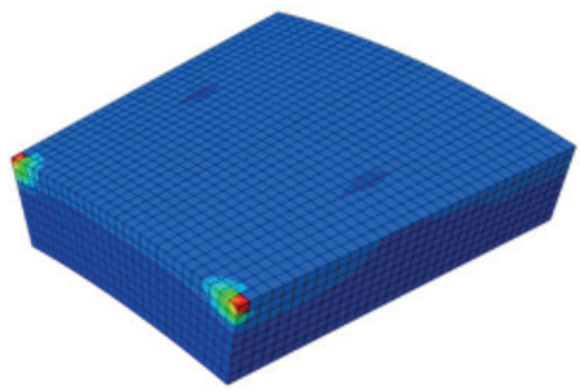

$\mathrm{b}$

Fig. 16 Damages of key and key - adjacent segments due to compressive stress a) Key - adjacent segment, b) Key segment

tunnel route. As can be seen in the Fig. 19, the insertion angle is increased from 7 to 22 degrees resulting in additional displacement of key segments along the $\mathrm{Z}$ direction. In fact, by increasing the insertion angle, the segment tends to get out of its place in the ring. The magnitude of displacement by itself is not very important, but the key point is the level of difference between the displacements of the key and key-adjacent segments. Fig. 20 indicates displacement of key and key-adjacent segments along $X$, $\mathrm{Y}$ and $\mathrm{Z}$ directions. As it can be concluded from this figure, the displacement of the parts is equal in both $\mathrm{X}$ and $\mathrm{Y}$ directions while the difference of displacements between key and key-adjacent segments are considerable along $\mathrm{Z}$ direction. If an assembly system is present at the longitudinal joints of the parts, there would be a high potential of chipping at these points. 

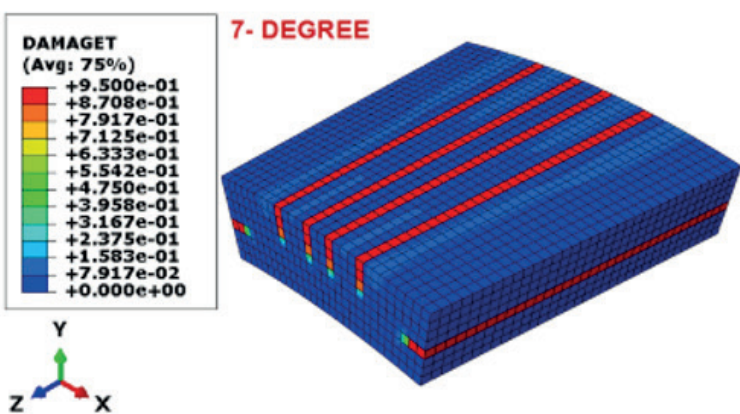

a
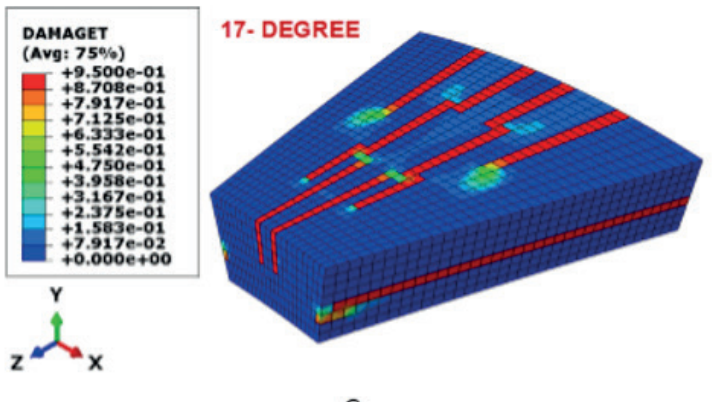
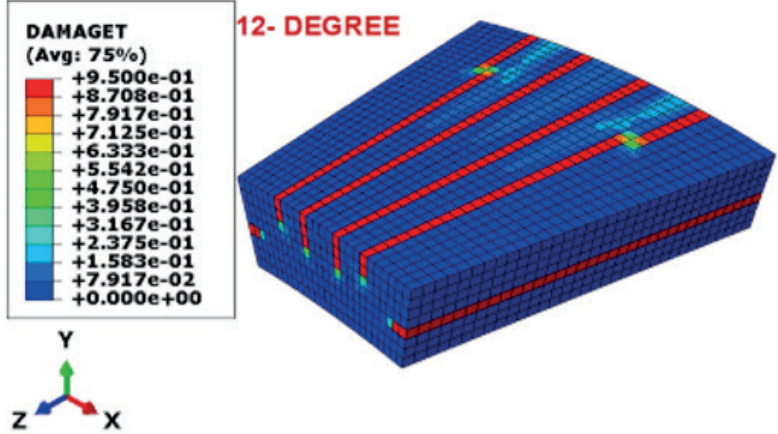

b

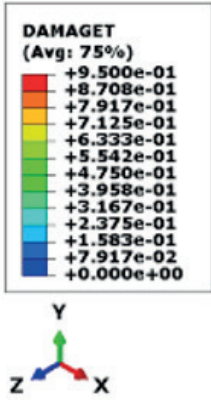

22- DEGREE

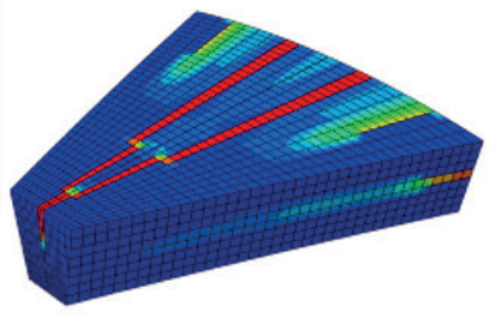

d

Fig. 17 Damages of key - segments due to tensile stress (key segment on the wall) a) 7 degree, b) 12 degree, c) 17 degree, d) 22 degree

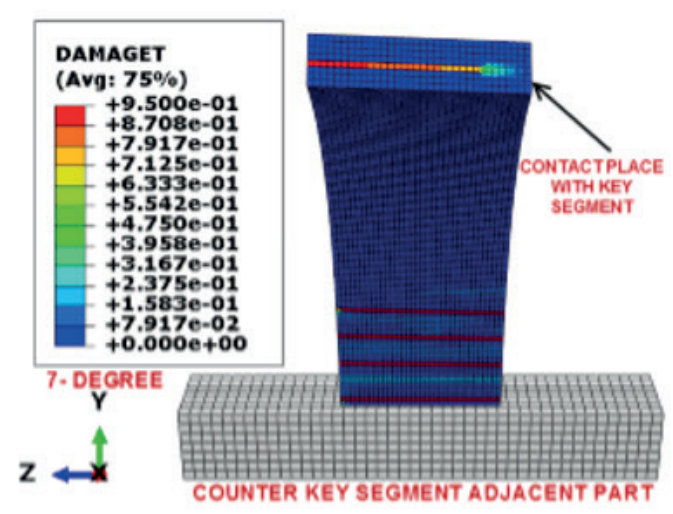

a

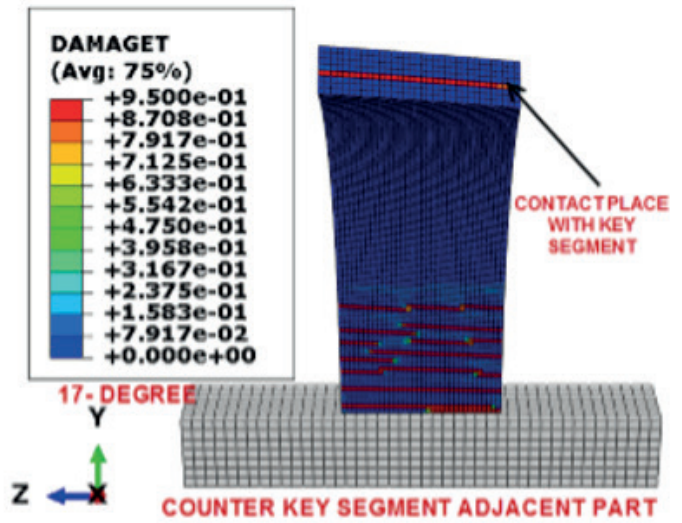

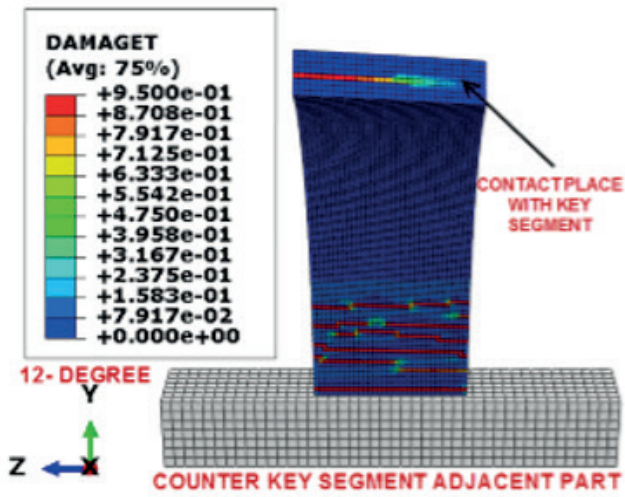

b

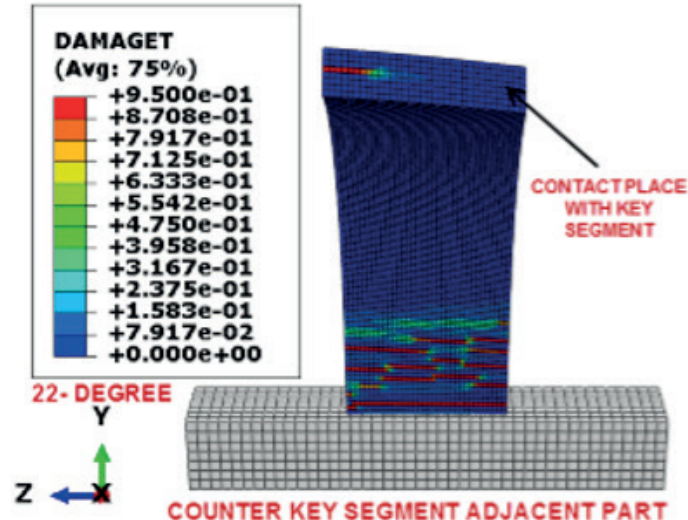

d

Fig. 18 Damages of key - adjacent segments due to tensile stress (key segment on the wall) Key segment insertion angles a) 7 degree, b) 12 degree,

c) 17 degree, d) 22 degree 


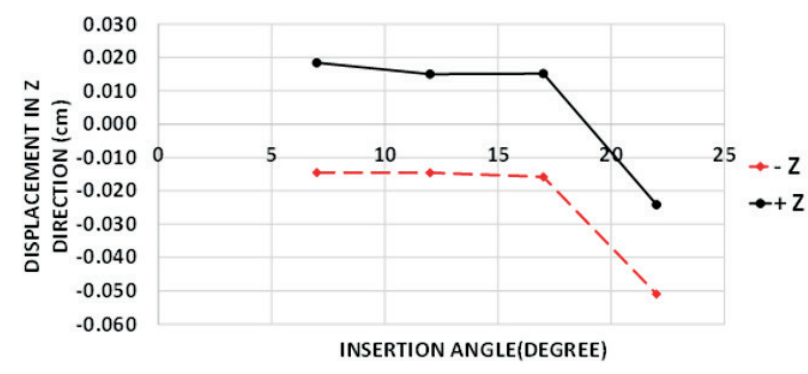

(a)

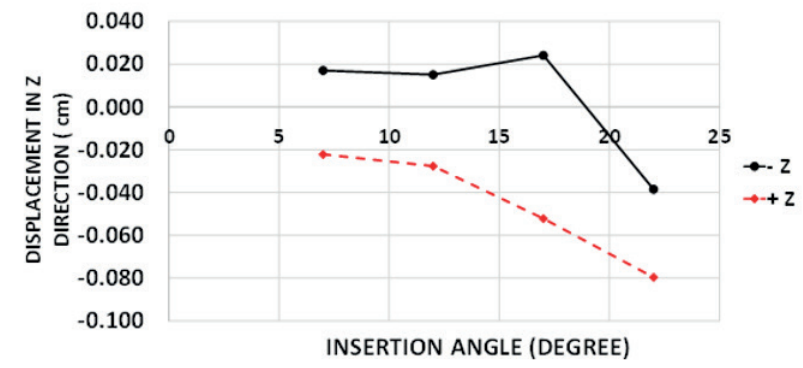

(b)

Fig. 19 Displacement of key-segments along z direction, a) Roof, b) Wall

Although the 22 degree key segment have minimum amount of damage in the two loading cases, which was mentioned earlier, it shouldn't be assumed that the main assumption in modeling is perfect installation of lining system with minimum tolerances. The erection of concrete segments has some degrees of tolerance known as installation tolerance, in practice. A non-uniform displacement of key and key-adjacent segments is possibly followed with a considerable amount of damage, particularly along $\mathrm{z}$ direction. This type of damage will be intensified especially when key segment has assembly system at the joints.

Examining the moment-rotational behavior of contact surface between the key and key-adjacent parts is another important issue which could be used to study the behavior of key segments based on the insertion angle. By examining this behavior, rigidity and maximum bending capacity of the joints could be extracted. Fig. 21 shows the moment-rotational curve of the segment with various insertion angles of 7, 12, 17 and 22 degrees. Fig. 21(a) is related to the key segment, which is placed on the top-center of the tunnel ceiling while Fig. 21(b) is associated with the same segment placed on the tunnel wall. According to these figures, increase in insertion angle from 7 to 22 degrees doesn't make considerable change in the ultimate strength of contact surfaces. Magnitude of the applied load, which has been chosen to extract the ultimate strength of segments, and also implementing the same magnitude and manner of loading in all of the models can be reasons for this behavior. It should be mentioned that the ultimate strength of

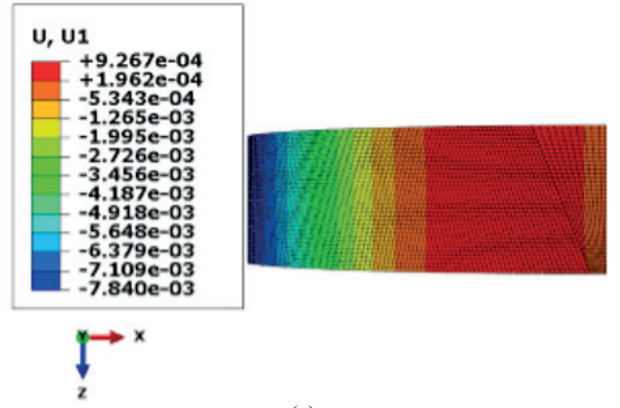

(a)

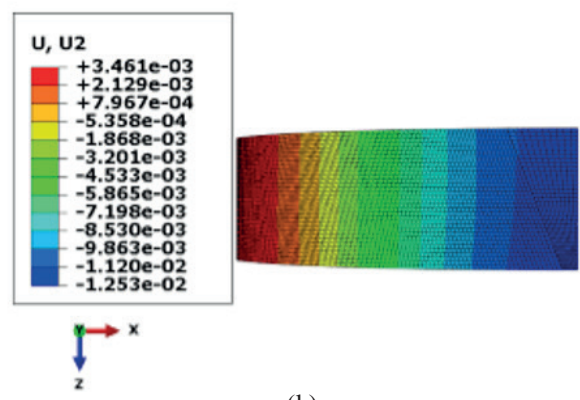

(b)

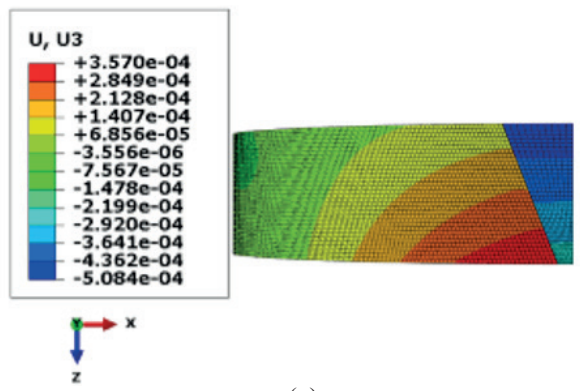

(c)

Fig. 20 Displacement differences between the key and key-adjacent segments (22 - degree key segment); a) Displacement in X-axis direction, b) Displacement in y-axis direction, c) Displacement in z-axis direction

contact surface when the key segment is placed on the ceiling is more than the condition, when the key segment is placed on the wall, because the axial load applied to the contact surface when the parts are on the ceiling is more than the case when concrete segments are on the wall.

Focusing on the linear part of the figures, it can be figured out that increase in insertion angle from 7 to 22 degrees, causes the slope of the linear part of the moment-rotational curves to be increased accordingly, which means increase in rigidity of the contact surfaces. In other words, the key segment with an insertion angle of 22 degrees at the same moment level, can tolerate less amount of rotation in comparison with other concrete segments. The reason for increase in rigidity level could be related to the surface area between the key and key-adjacent segments from 7 to 22 degrees of insertion angle. Exact alignment of the TBM's jacks with segments. 


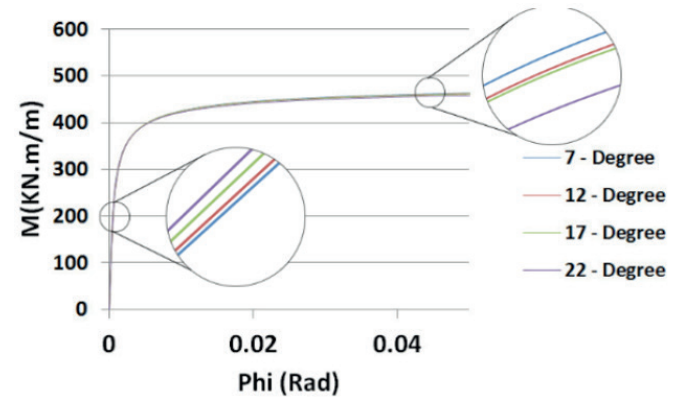

(a)

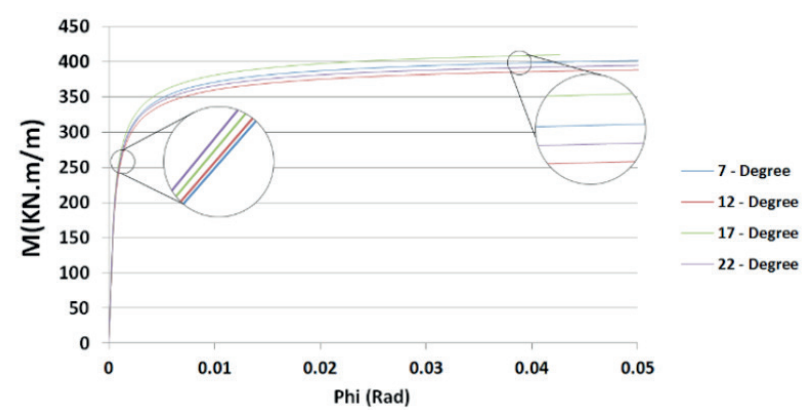

(b)

Fig. 21 Moment rotational curve of the joints between key and counterkey segments: a) Roof, b) Wall

Thrust jack model deals with the cracking of the concrete segments under TBM's jack forces. As it was mentioned earlier, excavation in curved routes of a tunnel or human mistake in installation of segments make it difficult obtain exact alignment of the TBM's jacks with segments.
Twelve numerical models have been prepared for thrust jack model. Four deviation angles between TBM's thrust jacks and segment's alignment which are 0, 5, 10 and 15 degrees and also four other deviations between centerline of concrete segments and TBM's thrust jacks which are 0 , 3 and $6 \mathrm{~cm}$ were considered in the current study Fig. 12(c).

Figs. 22 to 24 show result of thrust jack models. Figs. 22(a) to 22(d) are related to the models with $0-15$ degrees of deviation in alignments, respectively while the deviation between thrust jacks and the segments centerline is zero. The two other figures are similar to Fig. 22 while Fig. 23 and Fig. 24 present the models with 3 and $6 \mathrm{~cm}$ deviation in centerline, respectively. As it can be concluded from these figures, the amount of cracking is increased from 0 to 15 degrees deviation. The outcome of these models is in accordance with the results obtained through the statistical investigations. In fact, the modeled concrete segments got cracked at the same exact locations of the segments which are examined in Section 2.2. Furthermore, increase in deviation of centerlines results in chipping and stress concentration in bolt holes.

Minimum applied load, which results in concrete segment damage is also investigated in thrust jack model. Fig. 25 shows this factor based on deviations in alignments and centerlines. As it can be concluded from this figure, concrete segment's damage occurs in lower loads as the deviation in alignments and centerlines are increased. For

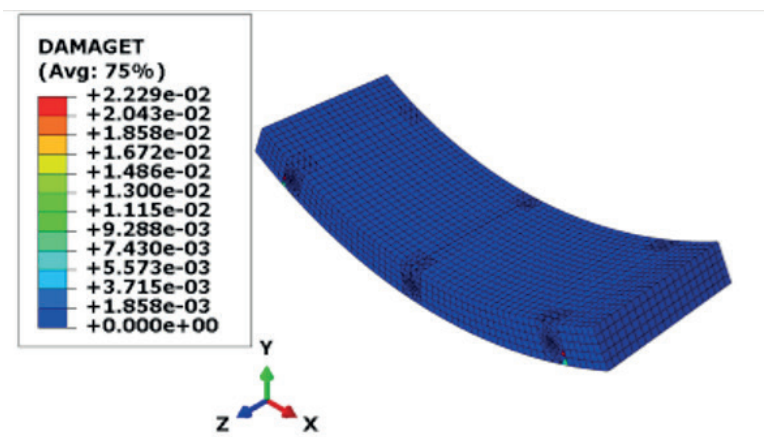

a

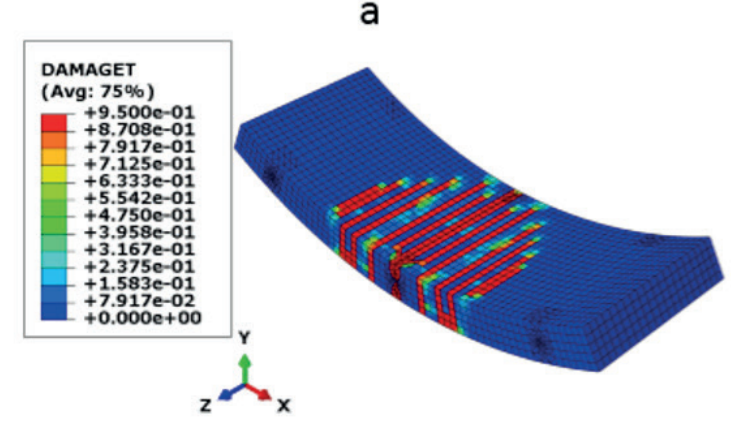

C

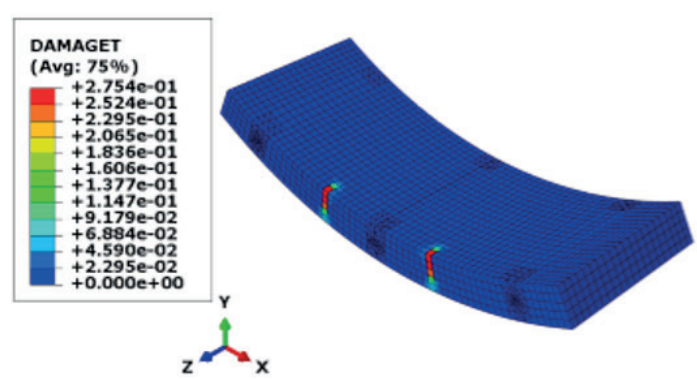

b

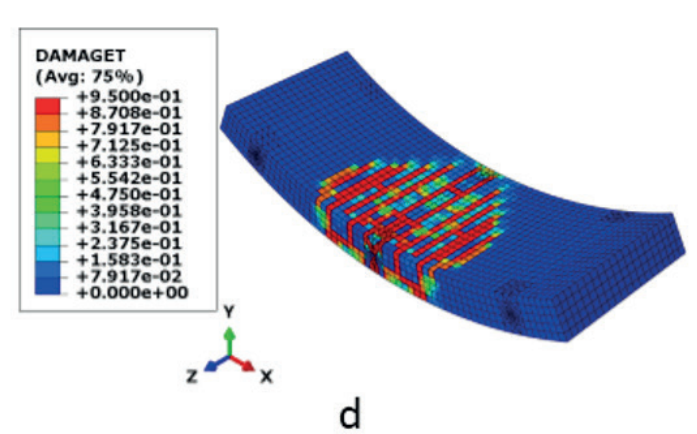

Fig. 22 Damages in concrete segments loaded with zero deviation and for thrust jack deviation angle a) 0 degree, b) 5 degree, c) 10 degree, d) 15 degree 


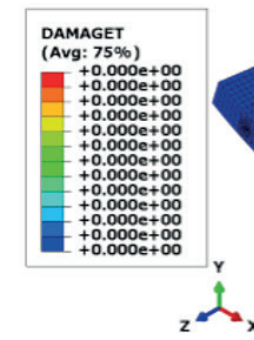

$\mathrm{z}_{\mathrm{x}}$

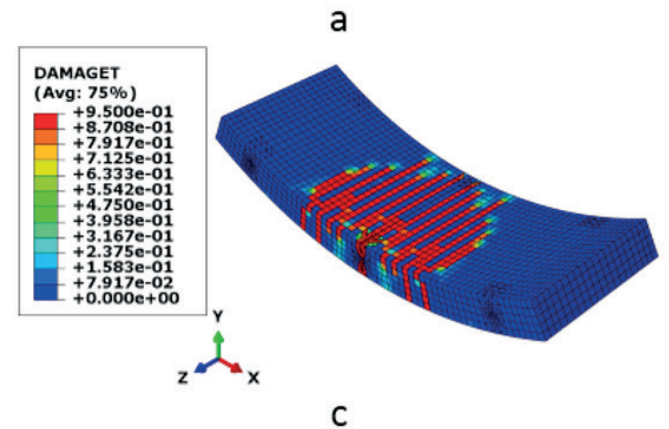

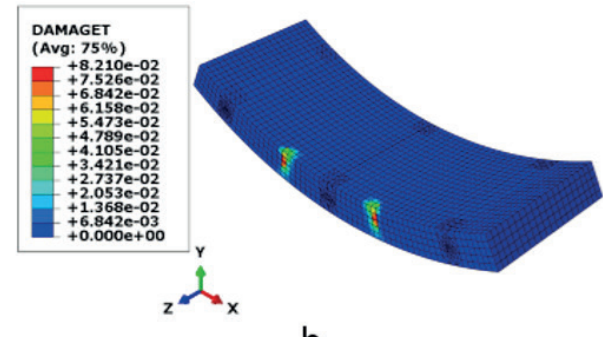

b

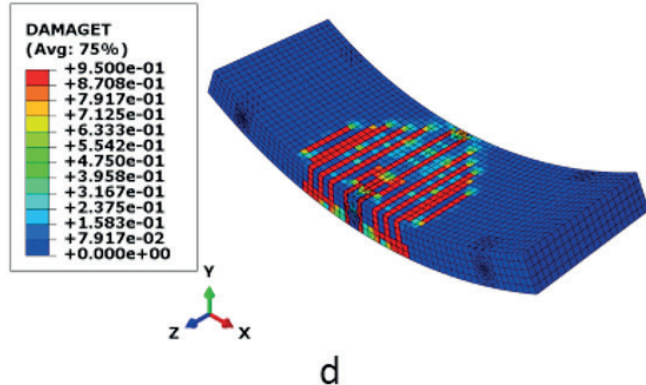

Fig. 23 Damages in concrete segments loaded with $3 \mathrm{~cm}$ deviation and for thrust jack deviation angle a) 0 degree, b) 5 degree, c) 10 degree, d) 15 degree

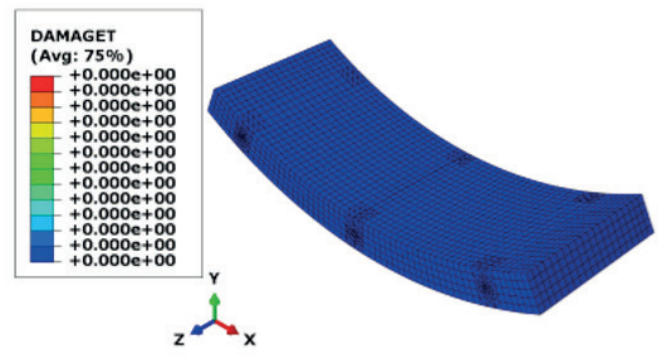

a

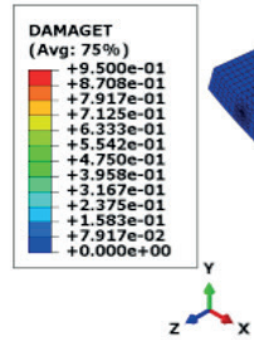

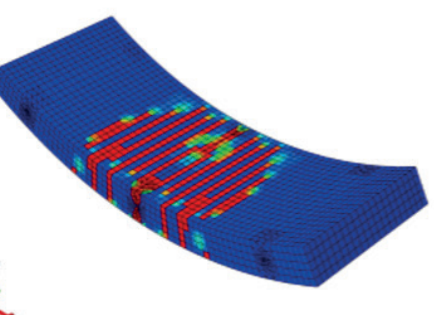

C

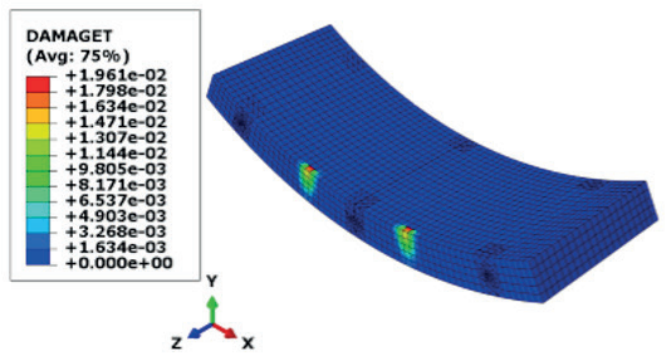

b

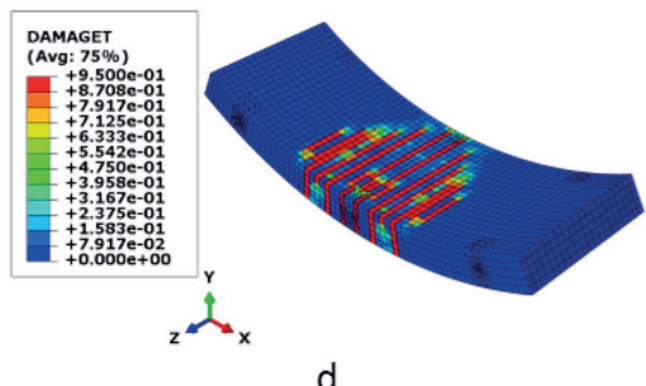

Fig. 24 Damages in concrete segments loaded with $6 \mathrm{~cm}$ deviation and for thrust jack deviation angle: a) 0 degree, b) 5 degree, c) 10 degree, d) 15 degree

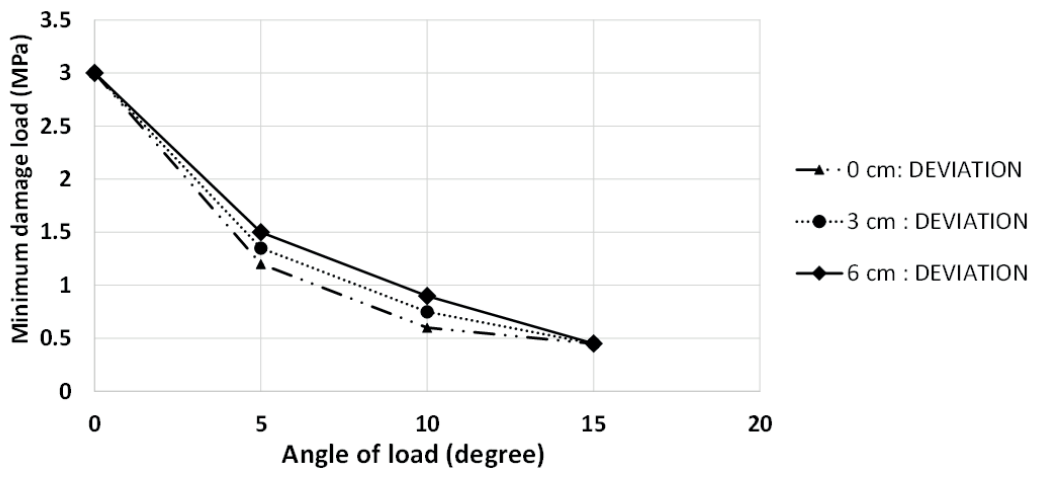

Fig. 25 Minimum load required to damage concrete segment 
instance, the segment could bear $3 \mathrm{MPa}$ load when the deviation in alignments is zero while the initiation load of damage decreases to $0.45 \mathrm{MPa}$ when the load angle increases to 15 degrees. It seems that in cases when the deviation is more than 5 degrees, even the best quality concrete segments with the highest strength wouldn't be able to stay undamaged. It is proposed to employ boring machines with articulated system in tunnels with small-radius curved routes (less than 300 meters).

\section{Conclusions}

Examination of chipping and cracking damages of concrete segments based on statistical data analyses and numerical modelling yields following conclusions:

- Corners of key-adjacent and key segments are highly vulnerable to chipping.

- Chipping at longitudinal joints might be result of contact between concrete segments of a ring. Lateral joints chipping could be caused by contact with TBM's jacks and contact between concrete segments in 2 adjacent rings.

- Cracking in concrete segments generally appears in middle zones.

\section{References}

[1] Guglielmetti, V., Grasso, P., Mahtab, A., Xu, S. (eds.) "Mechanized Tunneling in Urban Areas: Design Methodology and Construction Control", CRC Press, London, UK, 2008. https://doi.org/10.1201/9780203938515

[2] Gruebl, F. "Segmental Rings - Critical Loads and Damage Prevention", In: International Symposium on Underground Excavation and Tunnelling: Effect of Groundwater on Tunnel Stability, Bangkok, Thailand, 2006, pp. 9-19.

[3] Chen, J. S., Mo, H. H. "Numerical study on crack problems in segments of shield tunnel using finite element method", Tunnelling and Underground Space Technology, 24(1), pp. 91-102, 2009.

https://doi.org/10.1016/j.tust.2008.05.007

[4] Ahmadi, M. H., Mortazavi, A., Davarpanah, S. M., Zarei, H. "A Numerical Investigation of Segmental Lining Joints Interactions in Tunnels-Qomrud Water Conveyance Tunnel", Civil Engineering Journal, 2(7), pp. 334-347, 2016.

https://doi.org/10.28991/cej-2016-00000038

[5] Wu, H.-N., Shen, S.-L., Liao, S.-M., Yin, Z.-Y. "Longitudinal structural modelling of shield tunnels considering shearing dislocation between segmental rings", Tunneling and Underground Space Technology, 50, pp. 317-323, 2015.

https://doi.org/10.1016/j.tust.2015.08.001
- Shape of the concrete segments, and also number of thrust jacks are the factors which affect the magnitude and pattern of cracking.

- Increase in insertion angle of key segment from 7 to 22 degrees results in reduction of total amount of damage due to tensile stress. On the other hand, this change makes key-segment unstable in Z-direction. The fact causes serious chipping in assembly system's points even in situation with exact installation of tunnel lining. Key-segments with 12-17 insertion angles are proposed.

- Perfect installation of tunnel lining results in low amount of damage due to compressive stress.

- The moment-rotational behavior of contact surfaces between the key and key-adjacent segments doesn't show much difference when insertion angle changes from 7 to 22 degrees.

- Deviation in alignments of TBM's thrust jacks and segments result in serious damage due to tensile stress. Numerical model proved that the deviation shouldn't be more than 5 degrees, otherwise considerable damage is inevitable even in perfect concrete segments. Using TBM's with articulated system is proposed for tunnels with small-radius curves.

[6] Shayanfar, M. A., Mahyar, P., Jafari, A., Mohtadinia, M. "Classification of Precast Concrete Segments Damages during Production and Transportation in Mechanized Shield Tunnels of Iran", Civil Engineering Journal, 3(6), pp. 412-426, 2017.

https://doi.org/10.28991/cej-2017-00000101

[7] American Concrete Institute "209.1R-05: Report of Factors Affecting Shrinkage and Creep of Hardened Concrete", ACI Committee, Farmington Hills, MI, USA, 2005.

[8] Crespo, M. D., Molins, C., Marí, A. R. "Effect of variations in thermal-curing cycle on the cracking risk of precast segmental tunnel lining", Construction and Building Materials, 49, pp. 201-213, 2013. https://doi.org/10.1016/j.conbuildmat.2013.07.078

[9] SELI Overseas "Standard specifications for tunneling: Shield Tunnels", [online] Available at: http://www.selioverseas.com/ works.html

[10] Sugimoto, M. "Causes of shield segment damages during construction", In: International Symposium on Underground Excavation and Tunnelling: Effect of Groundwater on Tunnel Stability, Bangkok, Thailand, 2006, pp. 67-74.

[11] Ahmadi, M. H., Molladavoodi, H. "A micromechanical SlidingDamage Model under Dynamic Compressive Loading", Periodica Polytechnica Civil Engineering, 63(1), pp. 168-183, 2019. https://doi.org/10.3311/PPci.13249 
[12] Herrenknecht, M., Bäppler, K. "Segmental concrete lining design and installation", presented at Soft Ground and Hard Rock Mechanical Tunneling Technology Seminar, Golden, CO, USA, 2007.

[13] Blom, C. B. M. "Design philosophy of concrete linings for tunnels in soft soils", PhD Thesis, Delft University of Technology, 2002. [online] Available at: http://resolver.tudelft.nl/uuid:dee23627-1fb04308-a536-6120ae1e8db5

[14] Chen, J.-S., Mo, H. H. "Study on effect of segments erection tolerance and wedge-shaped segment on segment ring in shield tunnel", Journal of Zhejiang University-Science A, 7, pp. 1864-1869, 2006. https://doi.org/10.1631/jzus.2006.A1864

[15] Cavalaro, S. H. P., Blom, C. B. M., Walraven, J. C., Aguado, A. "Structural analysis of contact deficiencies in segmented lining", Tunnelling and Underground Space Technology, 26(6), pp. 734 749, 2011. https://doi.org/10.1016/j.tust.2011.05.004

[16] Mo, H. H., Chen, J. S. "Study on inner force and dislocation of segments caused by shield machine attitude", Tunneling and Underground Space Technology, 23(3), pp. 281-291, 2008. https://doi.org/10.1016/j.tust.2007.06.007
[17] Japan Society of Civil Engineers "Standard specifications for tunneling: Shield Tunnels", JSCE, Tokyo, Japan, 2007, [online] Available at: http://www.jsce-int.org/about/guideline

[18] Chang, C.-T., Wang, M.-J., Chang, C.-T., Sun, C.-W. "Repair of displaced shield tunnel of the Taipei rapid transit system", Tunneling and Underground Space Technology, 16(3), pp.167-173, 2001. https://doi.org/10.1016/S0886-7798(01)00050-5

[19] Protosenya, A. G., Lebedev, M. O. "Calculation of the Loads on Linings of Subway Tunnels Constructed in Physically Nonlinear soil Masses", Journal of Mining Science, 38, pp. 418-424, 2002. https://doi.org/10.1023/A:1023975313128

[20] Lubliner, J., Oliver, J., Oller, S., Oñate, E. "A plastic-damage model for concrete", International Journal of Solids and Structures, 25(3), pp. 299-326, 1989. https://doi.org/10.1016/0020-7683(89)90050-4

[21] Jankowiak, T., Łodygowski, T. "Identification of parameters of concrete damage plasticity constitutive model", Foundations of Civil and Environmental Engineering, 6, pp. 53-69. 2005. [online] Available at: https://www.researchgate.net/publication/228525599 Identification_of_parameters_of_concrete_damage_plasticity_constitutive model 